\title{
Screening and Comparison of Lignin Degradation Microbial Consortia from Wooden Antiques
}

\author{
Wen Zhang ${ }^{1, *,+}+\mathbb{D}$, Xueyan Ren ${ }^{2,3,+}$, Qiong Lei ${ }^{4}$ and Lei Wang ${ }^{2,3, *(\mathbb{D})}$ \\ 1 School of Biology and Environmental Engineering, Zhejiang Shuren University, Hangzhou 310015, China \\ 2 School of Engineering, Westlake University, Hangzhou 310024, China; renxueyan@westlake.edu.cn \\ 3 Institute of Advanced Technology, Westlake Institute for Advanced Study, Hangzhou 310024, China \\ 4 Jingzhou Conservation Center of Hubei Province, Wood Lacquer Protection Research Department, \\ Jingzhou 434020, China; leiqiong99@163.com \\ * Correspondence: gillianjay@126.com (W.Z.); wang_lei@westlake.edu.cn (L.W.); \\ Tel./Fax: +86-0571-88297098 (W.Z.); +86-0571-85278909 (L.W.) \\ + These authors contributed equally to this work.
}

Citation: Zhang, W.; Ren, X.; Lei, Q.; Wang, L. Screening and Comparison of Lignin Degradation Microbial Consortia from Wooden Antiques. Molecules 2021, 26, 2862. https:// doi.org/10.3390/molecules26102862

Academic Editor: Xuebing Zhao and Keke Cheng

Received: 6 April 2021

Accepted: 8 May 2021

Published: 12 May 2021

Publisher's Note: MDPI stays neutral with regard to jurisdictional claims in published maps and institutional affiliations.

Copyright: (c) 2021 by the authors. Licensee MDPI, Basel, Switzerland. This article is an open access article distributed under the terms and conditions of the Creative Commons Attribution (CC BY) license (https:// creativecommons.org/licenses/by/ $4.0 /)$.

\begin{abstract}
Lignin, which is a component of wood, is difficult to degrade in nature. However, serious decay caused by microbial consortia can happen to wooden antiques during the preservation process. This study successfully screened four microbial consortia with lignin degradation capabilities (J-1, J-6, J-8 and J-15) from decayed wooden antiques. Their compositions were identified by genomic sequencing, while the degradation products were analyzed by GC-MS. The lignin degradation efficiency of J-6 reached $54 \%$ after $48 \mathrm{~h}$ with an initial lignin concentration of $0.5 \mathrm{~g} / \mathrm{L}$ at $\mathrm{pH} 4$ and rotation speed of $200 \mathrm{rpm}$. The fungal consortium of J-6 contained Saccharomycetales (98.92\%) and Ascomycota $(0.56 \%)$, which accounted for $31 \%$ of the total biomass. The main bacteria in J-6 were Shinella sp. (47.38\%), Cupriavidus sp. (29.84\%), and Bosea sp. (7.96\%). The strongest degradation performance of J-6 corresponded to its composition, where Saccharomycetales likely adapted to the system and improved lignin degradation enzymes activities, and the abundant bacterial consortium accelerated lignin decomposition. Our work demonstrated the potential utilization of microbial consortia via the synergy of microbial consortia, which may overcome the shortcomings of traditional lignin biodegradation when using a single strain, and the potential use of J-6 for lignin degradation/removal applications.
\end{abstract}

Keywords: lignin degradation; microbial consortium; biomass; synergetic degradation

\section{Introduction}

Lignin, which is an aromatic heteropolymer that accounts for 15-30\% of lignocellulosic biomass, is the most abundant source of renewable aromatic carbon in nature [1]. Lignin consists of phenylpropane units combined with different types of linkages, including $\beta-\mathrm{O}-4$, $\alpha-\mathrm{O}-4,4-\mathrm{O}-5, \beta-\beta, \beta-5,5-5$, and $\beta-1$ [2]. It is a recalcitrant compound due to its high molecular weight, structural complexity, and relative insolubility. It can result in many adverse environmental consequences $[3,4]$. Waste water containing lignin that has been discharged from many industries (e.g., the paper industry, rice milling businesses, and traditional Chinese medicine businesses) has led to serious water pollution [5-7]. Agricultural wastes such as straw contain stable lignin, which limits the further application of cellulose and hemicellulose [4]. These biomass resources are often burned by farmers in China, which causes serious air pollution $\left(\mathrm{SO}_{2}, \mathrm{NO}_{2}, \mathrm{CO}_{2}\right.$, and $\left.\mathrm{CO}\right)$ in autumn and winter and affects human health [8]. Lignin degradation can help solve the environmental problems caused by lignin pollutant emissions or incineration [9]. At the same time, its degradation can improve the pretreatment efficiency of lignocellulose biomass, which results in the effective separation of cellulose, hemicellulose, and lignin and a mild conversion of biomass to bioenergy as well as other valuable products [3,10]. 
Currently, the main lignin degradation technologies are chemically, physically, and biologically based. Energy consumption during the physical processes is normally high and the chemical processes may cause secondary pollution from potential mismanagement of the chemicals used. On the other hand, the biodegradation method that uses some fungi and bacteria that have evolved in nature to deconstruct lignin is environmentally friendly and has relatively lower energy consumption [11,12].

Despite the above-mentioned advantages, the current lignin biodegradation approach has several drawbacks. The most active microbes with respect to lignin biodegradation that have been identified to date are fungi, such as those belonging to the white-rot or brown-rot families, which have been widely reported to be capable of decomposing wood [13]. However, these microorganisms often lack the capability required for industrial applications, such as fast growth rates [14]. Bacteria grow faster than fungi, and they have been reported to be able to produce high value-added products from lignin [15]. However, the decomposition and utilization of lignin by bacteria is limited [12]. To overcome this, researchers have tried to use protoplast technology to construct an inter-kingdom fusant (the protoplasts of fungi and bacteria were prepared, and then the cells were fused) [16]. They successfully prepared fusants of Enterobacter cloacae and Psathyrella candolleana to degrade alkali lignin [16]. However, the degradation efficiency of the fusants was sensitive to the environment, and their genetic stability was also not clear. In addition to living microorganisms, many enzymes involved in lignin degradation have been identified, such as laccase, lignin peroxidase $(\mathrm{LiP})$, manganese peroxidase $(\mathrm{MnP})$, dye-decolorizing peroxidase (DyP), and aryl-alcohol oxidase (AAO) $[17,18]$. Their mixtures have been used to degrade lignin [19] but with relatively high costs and nonuniversal adaptability for different substrates [20].

The decomposition of lignin in nature is a result of cooperation among fungi and bacteria in natural microbial consortia [21]. At present, more attention has been given to single lignin-degrading strains rather than to microbial consortia. Some studies have shown that microbial consortia have higher lignin degradation efficiencies than single strains [22,23] and that their ability to adapt to different environments is greater. For example, when treating different kinds of wastewater, the treatment efficiency of a microbial consortium is much higher than that of a single microorganism [24]. Given the potential advantages of microbial consortia, efficient lignin degradation by microbial consortia could be obtained by screening water-preserved wooden antiques from ancient graves [25]. As China has a long history and culture, large numbers of wooden antiques from various dynasties are unearthed each year. The hypotheses of our study are that carbohydrates such as cellulose and hemicellulose were consumed by microorganisms during long-term burial and that the remaining lignin created a good lignin-rich environment ( $>60 \%$ lignin content) for lignin-degrading microorganisms that could utilize lignin as a carbon source [26]. After these wood antiques were unearthed, they were soaked in water for further preservation to avoid dry shrinkage and deformation. During the process of burial and preservation after excavation, a continuous water-saturated state is helpful for microorganism survival, while the water-preserved wooden antiques are further decomposed [27]. Thus, it is feasible to obtain the lignin-degrading microbial consortia from samples of water-saturated preserved wood antiques.

In this study, several lignin-degrading microbial consortia were screened that were obtained from different wooden antique samples. Their degradation characteristics, consortium structures, and lignin degradation products were analyzed and compared. The findings from this research support further investigations of which consortia are best for use in biomass treatment for biofuel and biogas production, in the pulping process, and in treating lignin-rich wastewater from the paper industry, compositing leachates, rice milling sites [7], and traditional Chinese medicine businesses. 


\section{Results}

\subsection{Screening of Lignin-Degrading Microbial Consortia}

The wooden antiques were preserved in water. Solid samples were obtained from pieces that fell off during the soaking process, and liquid samples were obtained from the soaking water. The typical color changes of microbial consortia in the guaiacol screening experiment are shown in Figure 1. According to the guaiacol color test, the lignin degradation efficiency by rotation incubation should be higher than that by static incubation. It was also observed that the $\mathrm{pH}$ of the basic culture medium increased during microbial consortium incubation. Among 40 samples, four microbial consortia, namely, J-1, J-6, J-8 and J-15, with the best performance were obtained after screening.

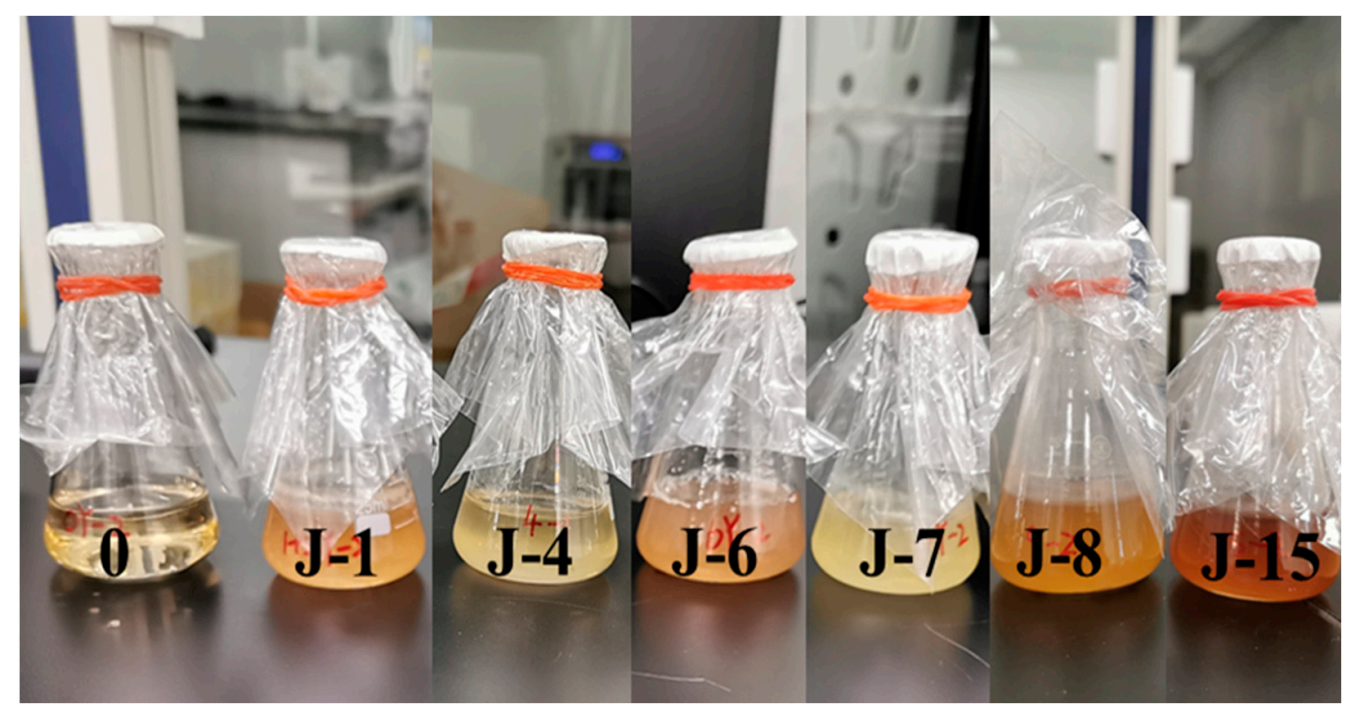

Figure 1. Color changes of different microbial consortiums in the guaiacol screening experiment.

\subsection{Comparative Study of the Lignin Degradation Performance of Different Microbial Consortia}

To study the lignin degradation effects of the four selected microbial consortia under different conditions, their lignin degradation performances were studied. The control was defined as the same operational mode without adding microorganisms. The results showed that the lignin concentrations remained unchanged in the control.

The effect of glucose on lignin degradation by different microbial consortia was studied. The results showed that lignin with added glucose greatly improved the degradation efficiency when compared with lignin alone and reached higher efficiencies on the 1st, 2nd, and 6th days (Figure 2). In the follow-up experiments, glucose degradation system was still selected.

The effect of initial $\mathrm{pH}$ on lignin degradation by different microbial consortia was studied. The lignin degradation performance was best when the initial $\mathrm{pH}$ of the culture medium was 4 (Figure 3). Under conditions with a $\mathrm{pH}$ value $=4$, the lignin degradation efficiency of J-6 reached $52.6 \%$ after $48 \mathrm{~h}$ and $53.7 \%$ on the 6 th day. The degradation rates of the other microbial consortia reached $30 \%(\mathrm{~J}-1), 34 \%(\mathrm{~J}-8)$, and $37.5 \%(\mathrm{~J}-15)$ on the 6 th day. Degradation experiments under optimal $\mathrm{pH}$ conditions also further confirmed that the degradation efficiencies on the 1st and 2nd days were often higher and then reached a plateau on the 6th day (Figure 4). 

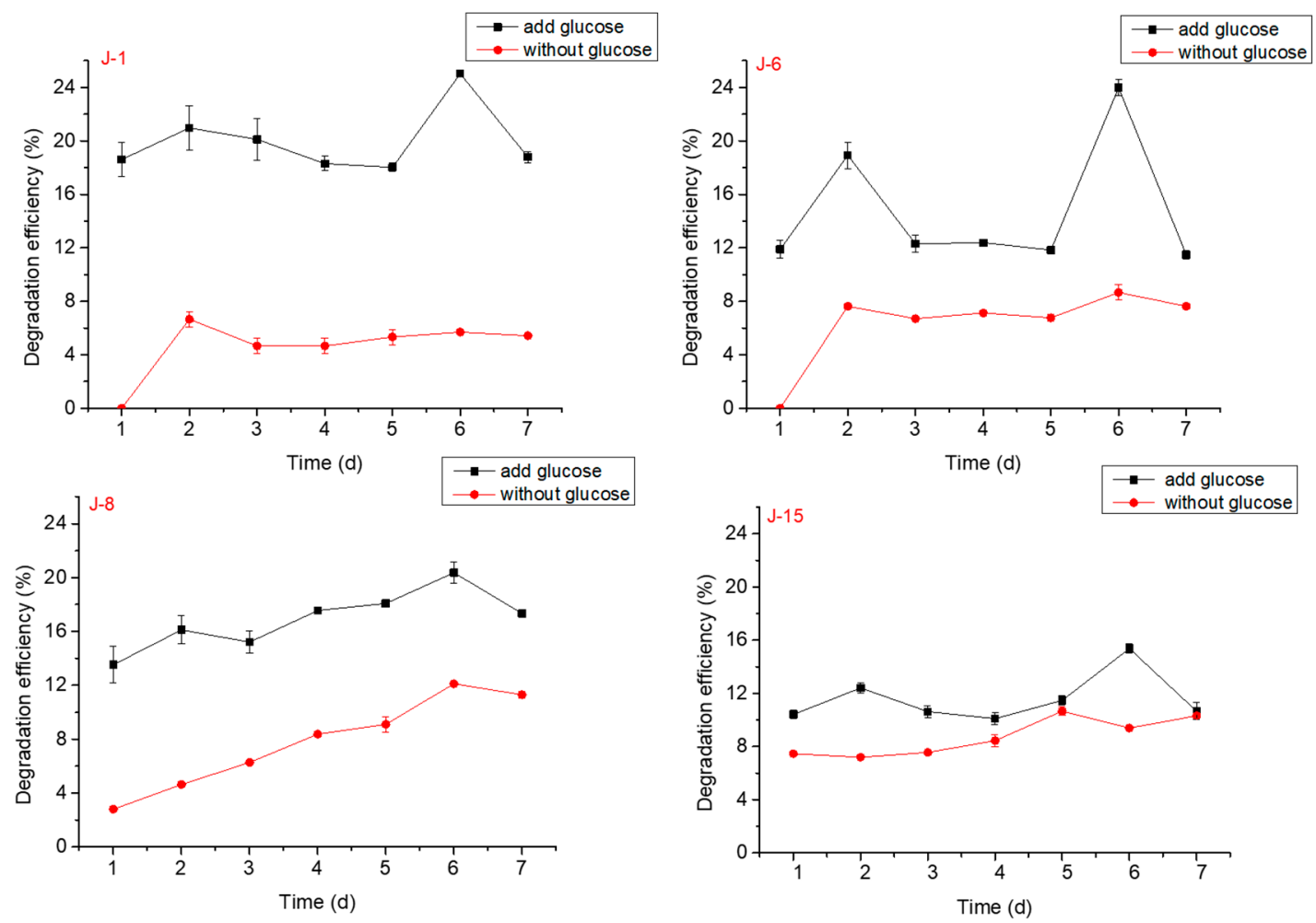

Figure 2. Effect of glucose on lignin degradation by J-1, J-6, J-8, and J-15 (pH =6, rotation speed = $160 \mathrm{rpm}$; initial lignin concentration $=0.5 \mathrm{~g} / \mathrm{L}$ ).
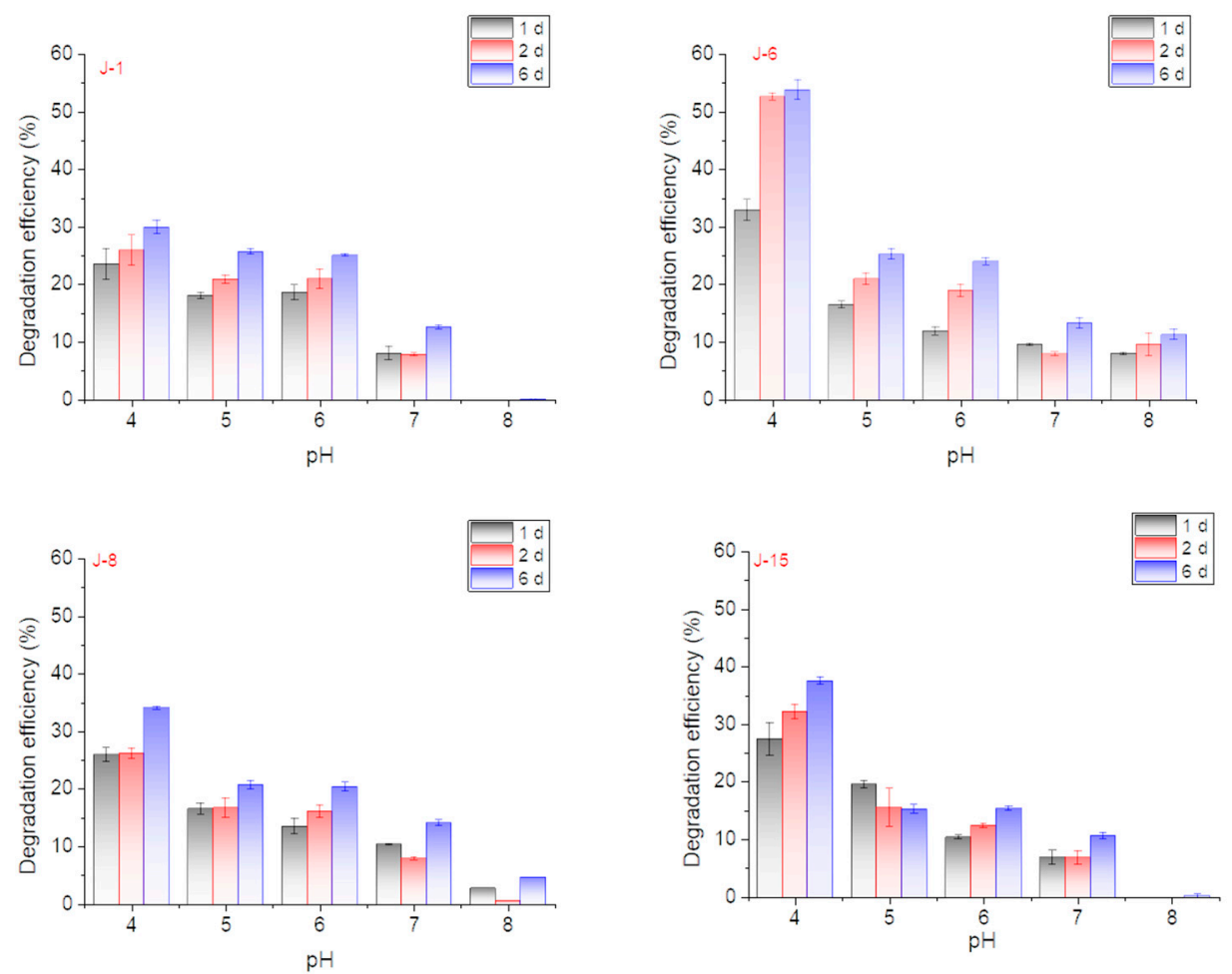

Figure 3. Effect of initial $\mathrm{pH}$ on lignin degradation efficiency by $\mathrm{J}-1, \mathrm{~J}-6, \mathrm{~J}-8$, and $\mathrm{J}-15$ (rotation speed $=160 \mathrm{rpm}$, initial lignin concentration $=0.5 \mathrm{~g} / \mathrm{L}$ ). 


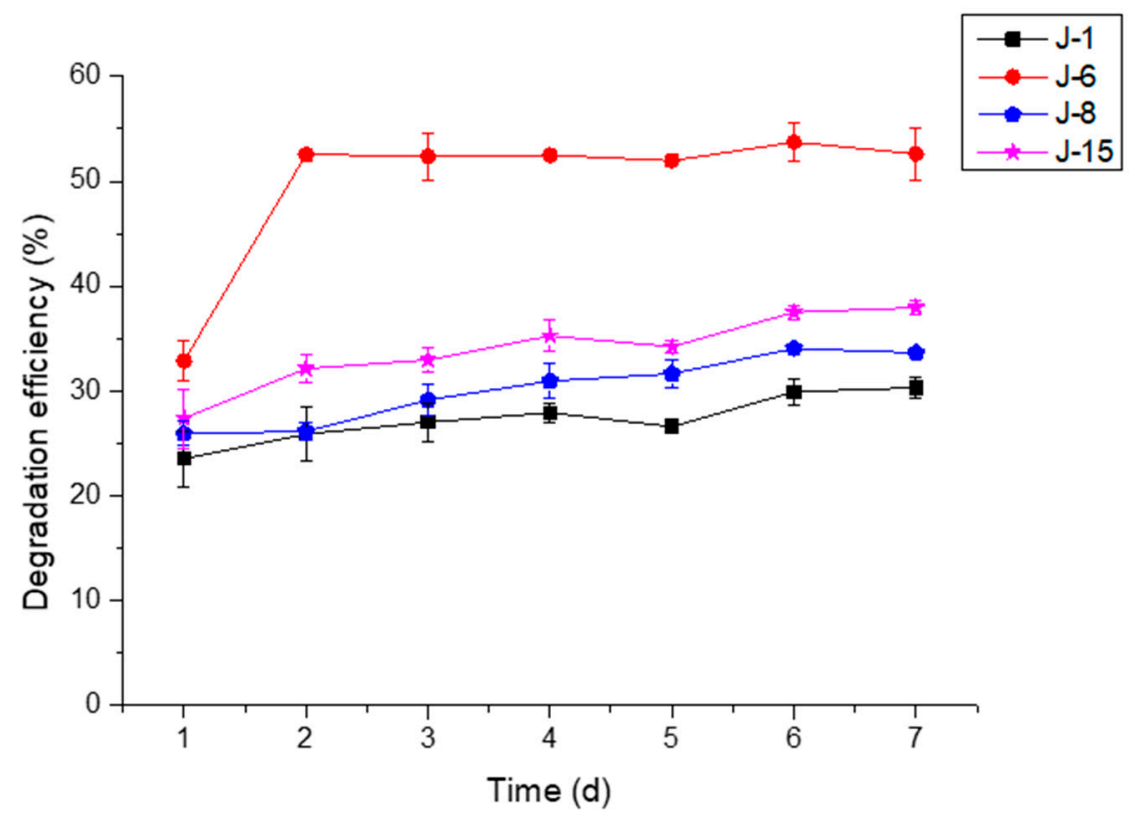

Figure 4. Effect of treatment time on lignin degradation by J-1, J-6, J-8, and J-15 ( $\mathrm{pH}=4$, rotation speed $=160 \mathrm{rpm}$, initial lignin concentration $=0.5 \mathrm{~g} / \mathrm{L}$ ).

Previous experiments have shown that microorganisms have a certain demand for oxygen in the processes of growth and lignin utilization because higher degradation efficiencies were achieved by rotation incubation. In this research, the effect of rotation speed on lignin degradation is shown in Figure 5. The results showed that the lignin degradation efficiencies of all microbial consortia reached $45 \%$ at $200 \mathrm{rpm}$ on the 6th day. However, J-8 and J-15 also exhibited good performances at low rotation speeds.
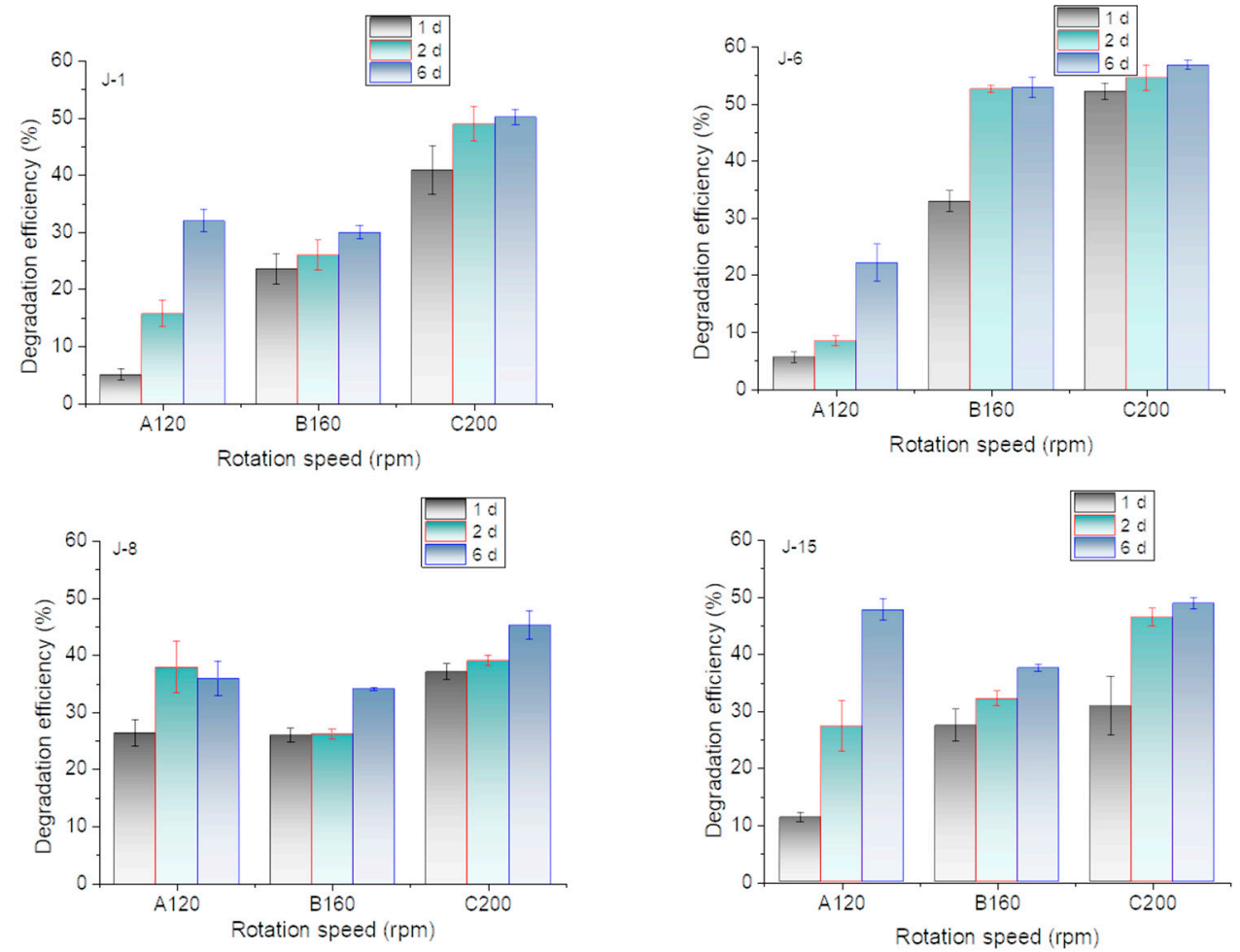

Figure 5. Effect of rotation speed on lignin degradation efficiency by $\mathrm{J}-1, \mathrm{~J}-6, \mathrm{~J}-8$, and $\mathrm{J}-15$ ( $\mathrm{pH}=4$, initial lignin concentration $=0.5 \mathrm{~g} / \mathrm{L}$ ). 
The effects of lignin concentrations on the lignin degradation efficiencies of the four microbial consortia are shown in Figure 6. In the initial experiments, the lignin concentration was $0.5 \mathrm{~g} / \mathrm{L}$. When lignin concentrations were higher than $0.5 \mathrm{~g} / \mathrm{L}$, the lignin degradation efficiencies of the four microbial consortia decreased. When lignin concentrations were lower than $0.5 \mathrm{~g} / \mathrm{L}$, the lignin degradation efficiency of J-8 improved on the 6th day, while those of J-1 and J-6 decreased significantly and that of J-15 decreased slightly. According to one-way ANOVA with Tukey's test, the lignin concentration had a significant impact on the degradation efficiency of J-1 and J-6 but not on J-8 and J-15.
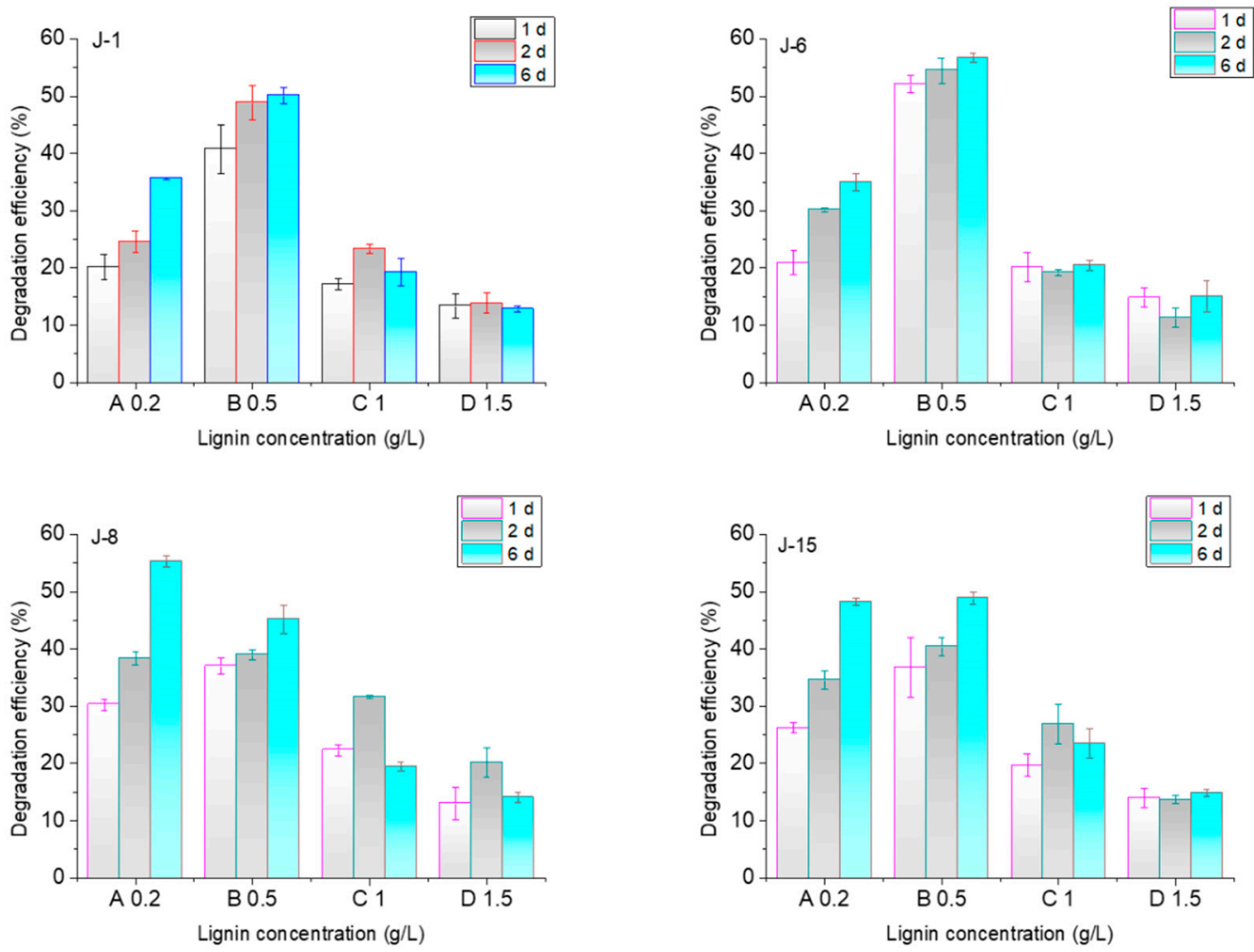

Figure 6. Effect of initial lignin concentration on lignin degradation efficiency by J-1, J-6, J-8, and J-15 $(\mathrm{pH}=4$, rotation speed $=200 \mathrm{rpm})$.

At the same time, degradation experiments at different temperatures were also carried out. The results showed that temperature had a negligible effect on lignin degradation within a temperature range of $25-35{ }^{\circ} \mathrm{C}$.

Furthermore, the results of lignin degradation enzyme activity tests of the four microbial consortia at different times are shown in Figure 7. The enzyme activity changes of the three important enzymes in the process of lignin degradation differed. For laccase, the enzyme activities of the four microbial consortia J-1, J-6, J-8, and J-15 were higher on the 1 st and 2 nd days and decreased significantly on the 6 th day. For lignin peroxidase (LiP), J-1 and J-6 reached the highest enzyme activity on the 6th day. For manganese peroxidase $(\mathrm{MnP})$, the activity was higher on the 1st day and 2nd day but decreased significantly on the 6 th day. 


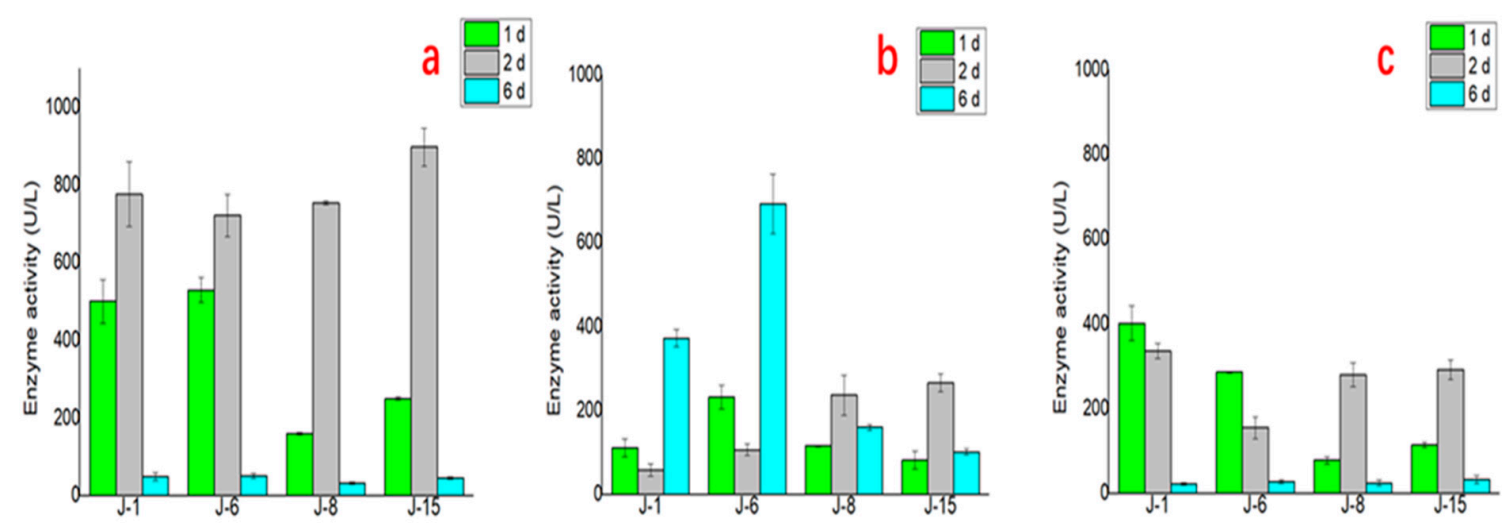

Figure 7. The lignin degradation enzyme activity test of the four microbial consortiums at different times ((a): laccase; (b): $\mathrm{LiP} ;(\mathbf{c}): \mathrm{MnP})$.

\subsection{Comparative Study of the Consortium Composition}

\subsubsection{Comparison of the Fungal Consortium Composition}

According to genomic sequencing analyses, the consortium compositions of the four groups are shown in Figure 8a. At the genus level, the fungi of J-1 were composed of Saccharomycetales $98.56 \%$ and Sordariomycetes $1.43 \%$. The fungi of J-6 were composed of Saccharomycetales $98.92 \%$ and Ascomycota $0.56 \%$. The fungi of J-8 included Ascomycota 98.15\% and Graphium sp. 1.63\%. The fungi of J-15 included Xenoacremonium sp. 65.61\%, Papiliotrema sp. $29.33 \%$, Fusarium sp. $3.08 \%$, and Trichoderma sp. $1.93 \%$.

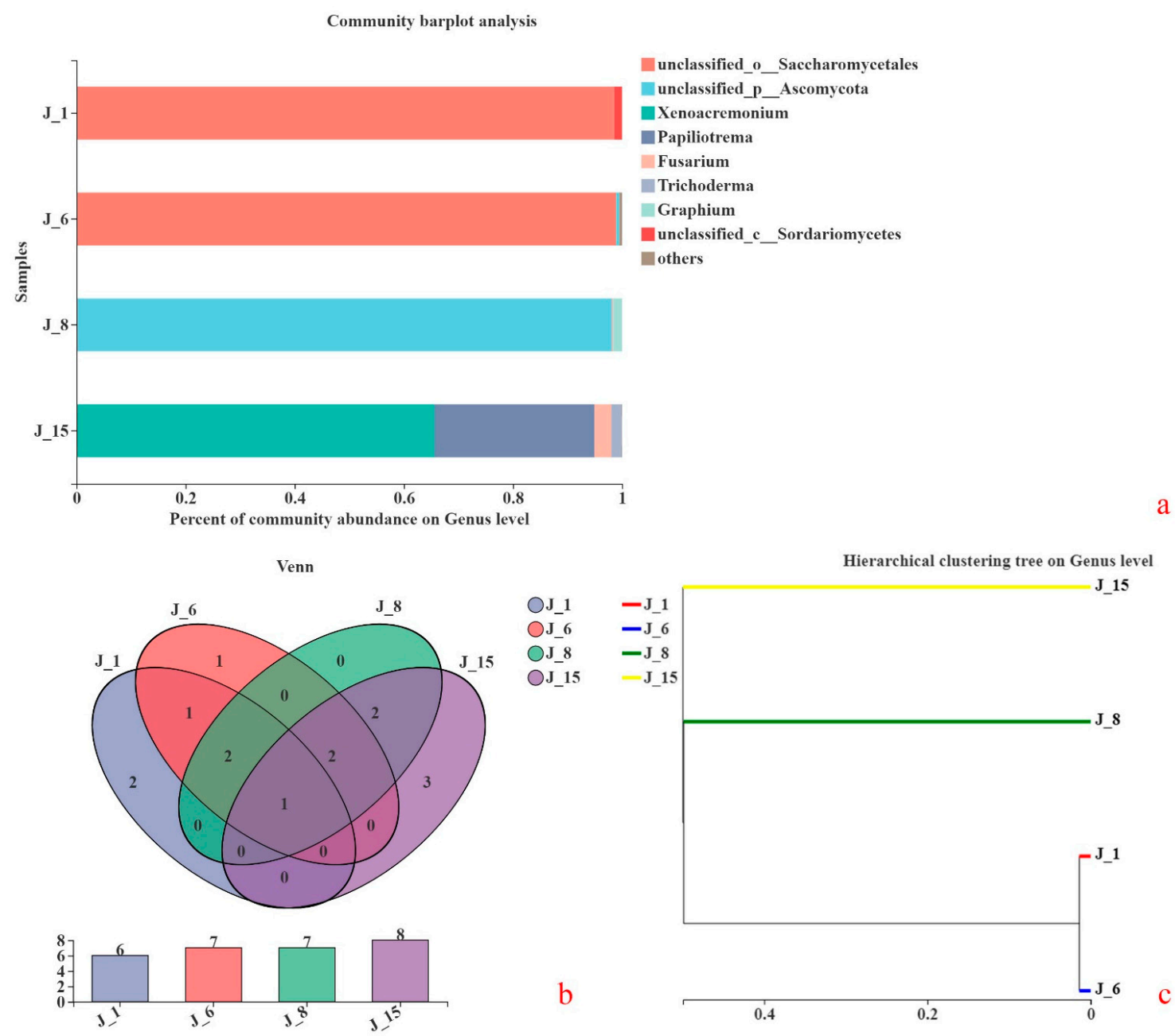

Figure 8. Comparison of fungal consortium composition ((a): consortium structure; (b): Venn diagram; (c): cluster analyses). 
A Venn diagram was used to count the fungal compositions of the four groups, as shown in Figure 8b. In general, Operational Taxonomic Units (OTUs) with a similarity level of $97 \%$ were selected for analysis. A Venn diagram was used to calculate the number of common and unique species in multiple groups or samples. Mortierella sp. was found in $\mathrm{J}-1, \mathrm{~J}-6, \mathrm{~J}-8$, and $\mathrm{J}-15$ based on the sequencing results.

To study the similarities or differences among different sample consortium structures, cluster analysis was carried out on the sample consortium distance matrix, and a sample hierarchical clustering tree was also constructed (Figure 8c). The UPGMA (unweighted pair group method with arithmetical mean) algorithm was used to construct a tree structure to visually represent the degrees of similarity or difference in the consortium compositions of different environmental samples. The consortium compositions of J-1 and J-6 were very close but were quite different from those of J-8 and J-15. Differences between J-8 and J-15 were also obvious.

According to the Circos sample and species relationship diagram (Figure 9), Saccharomycetales in J-1 and J-6 accounted for $100 \%$ of the total amount of Saccharomycetales in the four groups. Ascomycota in J-8 accounted for $99 \%$ of the total Ascomycota in the four groups, and Fusarium sp. and Trichoderma sp. in J-15 accounted for the majority (more than $90 \%)$.

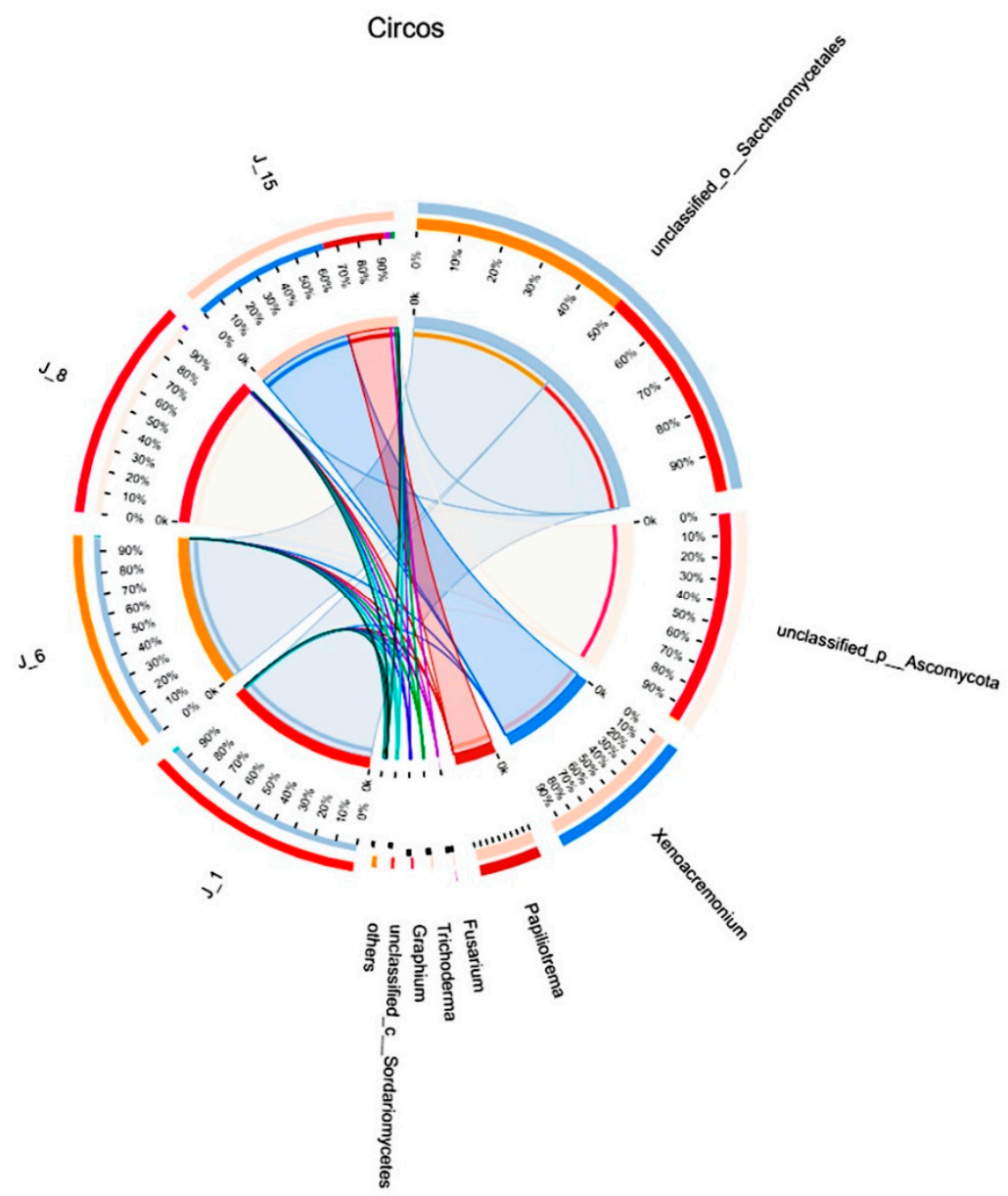

Figure 9. Circos sample and species relationship diagram.

To determine the effect of yeast on the activity of lignin-degrading enzymes, J-6 cells were treated with nystatin to inhibit yeast activity. Then, the J-6 bacterial consortium was cultured and transferred to a lignin degradation medium to compare the changes in lignin degradation enzyme activity. The results (Figure 10) showed that, when compared with the original J-6 microbial consortium, the activities of lignin-degrading enzymes, 
especially laccase and LiP, decreased significantly in the degradation medium of the J-6 bacterial consortium.
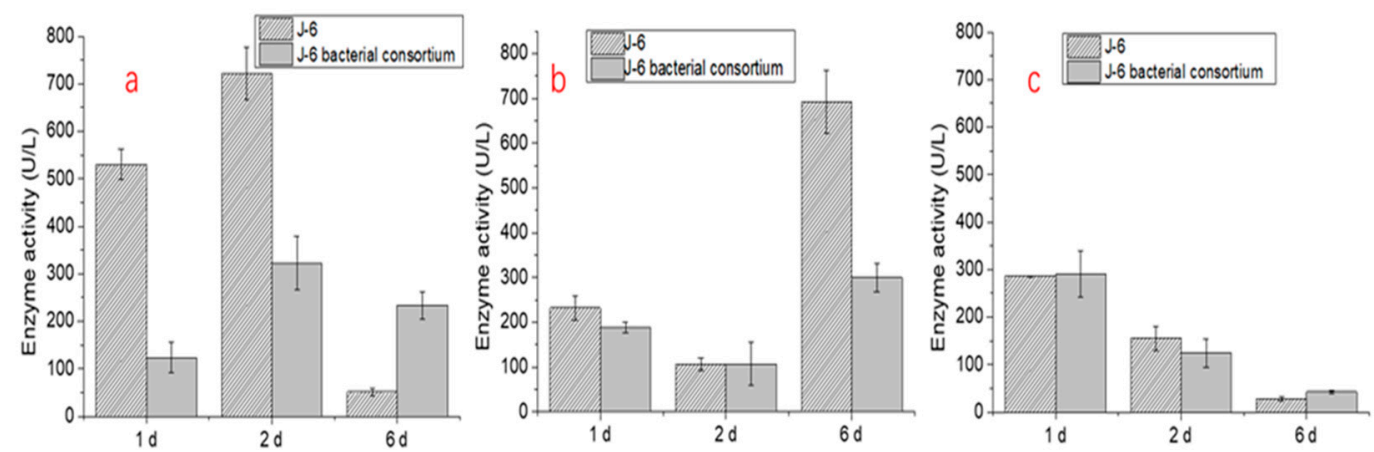

Figure 10. Lignin degradation enzyme activity of the original J-6 microbial consortium and J-6 bacterial consortium ((a): laccase; (b): LiP; (c): MnP).

\subsubsection{Comparison of the Bacterial Consortium Composition}

The bacterial compositions of the four microbial consortia were analyzed, and their consortium structures are shown in Figure 11a. The bacterial composition of J-1 was as follows: Serratia sp. $95.23 \%$ and Yersinia sp. 2.33\%. The bacterial composition of J-6 was Shinella sp. $47.38 \%$, Cupriavidus sp. $29.84 \%$, Bosea sp. $7.96 \%$, and Bacillus sp. $4.39 \%$. The bacterial composition of J-8 was Serratia $92.59 \%$, Alcaligenaceae $7.40 \%$ and Cupriavidus sp. $0.1 \%$. The bacterial composition of J-15 was Alcaligenaceae $32.85 \%$, Brucella sp. $49.74 \%$, Cupriavidus sp. $10.49 \%$, and Rhodococcus sp. $1.92 \%$.

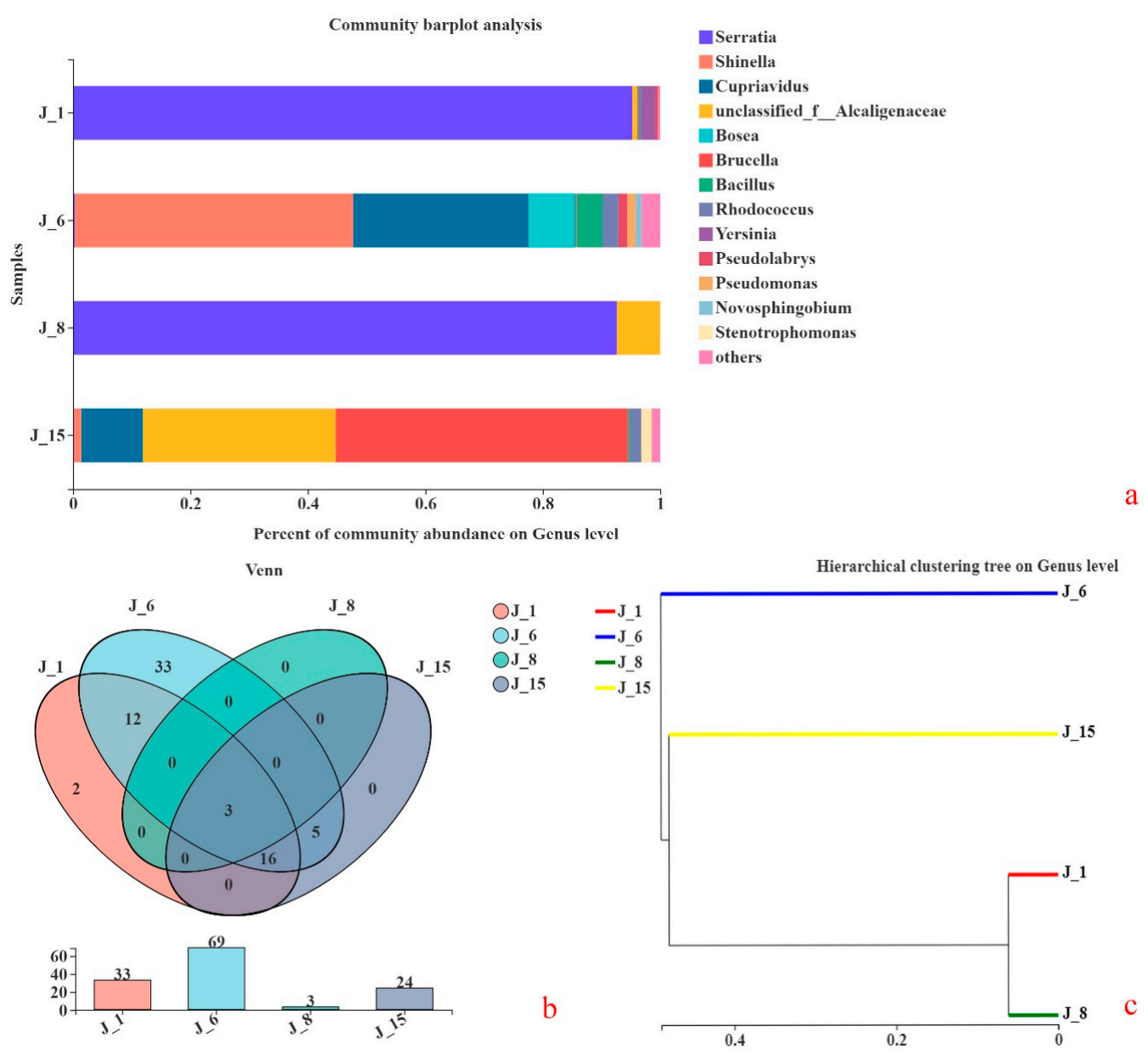

Figure 11. Comparison of bacterial consortium composition ((a): consortium structure; (b): Venn diagram; (c): cluster analyses). 
A Venn diagram was used to count the bacterial compositions of the four groups, as shown in Figure 11b. The common species of J-1, J-6, J-8, and J-15 were Alcaligenaceae, Cupriavidus sp. and Serratia sp.

In addition, cluster analyses were carried out on the sample consortium distance matrix to construct a sample hierarchical clustering tree. The results are shown in Figure 11c. $\mathrm{J}-1$ and J-8 show very similar bacterial composition, whereas both J-6 and J-15 are different in their composition.

A color gradient was utilized in a heatmap to represent the information for species compositions and abundances (Figure 12). J-6 had the highest abundance, while J-8 had the lowest bacterial abundance. J-6 mainly included Shinella sp., Cupriavidus sp., Bosea sp., Bacillus sp., Rhodococcus sp., and Pseudomonas sp.

Community heatmap analysis on Genus level

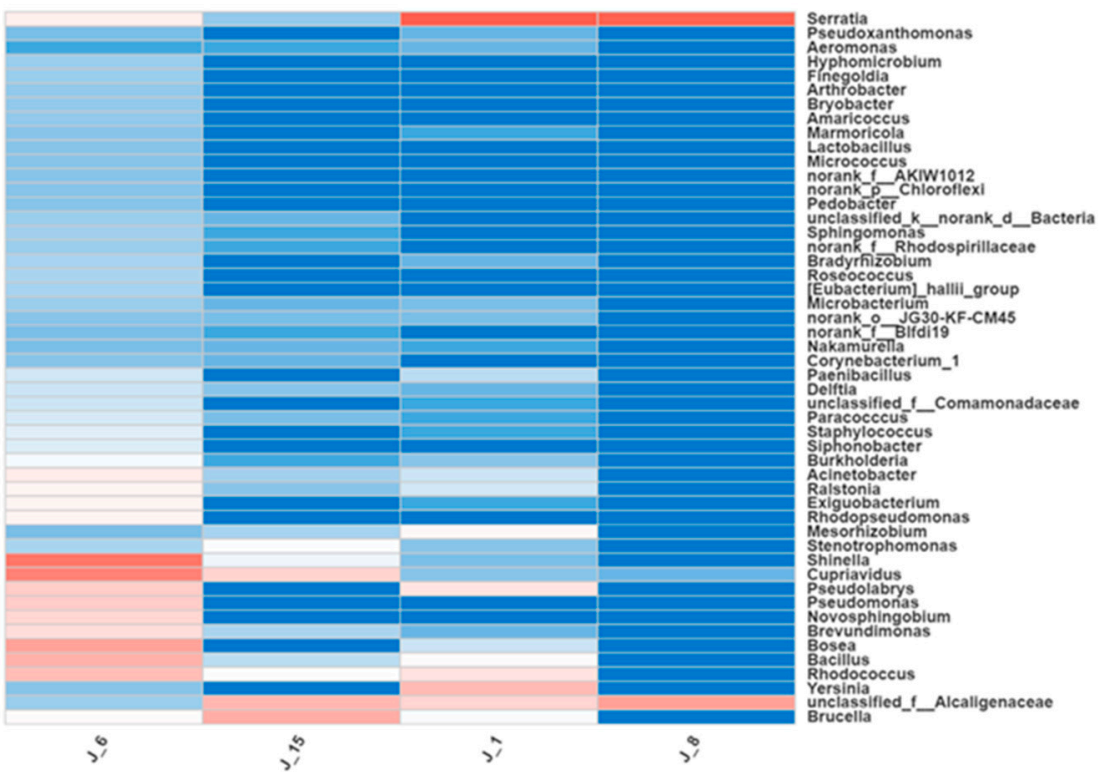

Figure 12. Heatmap of bacterial composition.

\subsection{Comparison of the Biomass of Fungi and Bacteria in the Microbial Consortia}

The biomass results showed that the fungal biomass of J-8 and J-15 accounted for $66 \%$ and $84 \%$ of the total biomass, respectively, while those of J-1 and J-6 accounted for $40 \%$ and $31 \%$ of the total biomass, respectively. In addition, microscopic examination (Figure 13) showed that fungal hyphae developed in J-8 and J-15, while J-1 and J-6 contained oval and spherical single cells, and no large fungal hyphae were present.

\subsection{Comparison of the Lignin Degradation Products}

The degradation products of each degradation group were further studied. Samples were obtained after the 1st, 2nd, and 6th days of degradation. The results are shown in Table 1. Each microbial consortium formed different degradation products. The types of products studied included not only the final products but also some intermediate products of the metabolic processes. For example, the specific products of J-1 included 2-[2-[3,4,5trimethoxyphenyl] ethenyl]-5,6,7,8-tetramethoxy-3-methyl-chromone. The specific products of J-6 included 2-methoxy-4-vinylphenol and benzenebutyric acid, 2,3-dimethoxyThe specific products of J-8 included 3-hydroxybenzoic acid and 5,5'-dimethoxy-3,3', 7,7' tetramethyl-2,2'-binaphthalene-1,1' $1^{\prime}, 4,4^{\prime}$-tetrone. The specific products of J-15 included 1,2-benzenedicarboxylic acid and butyl octyl ester. Lignin degradation by J-6 was relatively complete, and there were no degradation products that contained multiple benzene rings. 

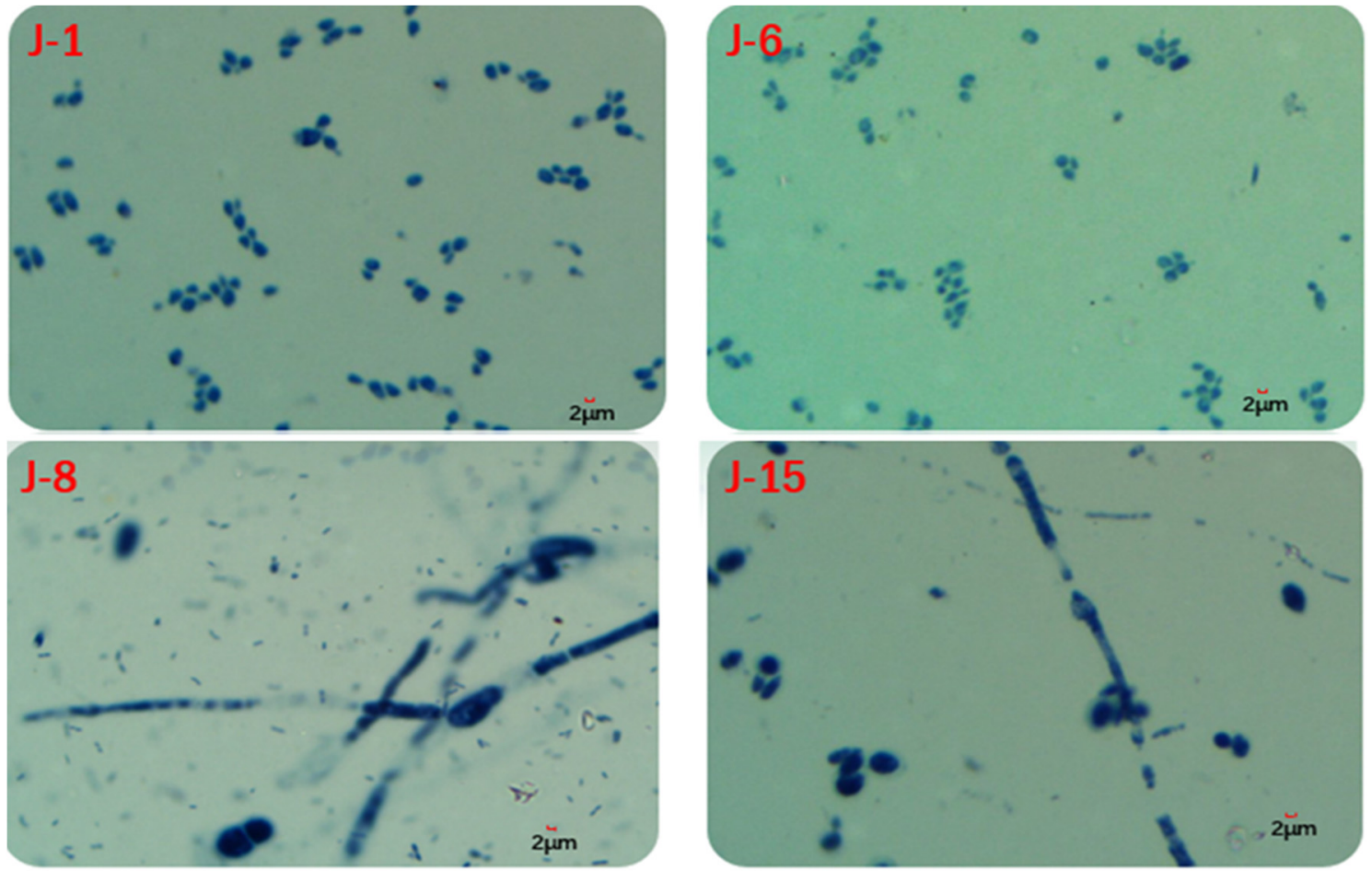

Figure 13. Microscopic examination of lignin degradation microbial consortiums.

Table 1. Identification of the metabolic products.

\begin{tabular}{|c|c|c|c|c|c|c|c|c|c|c|c|c|c|c|}
\hline \multirow{2}{*}{ No. } & \multirow{2}{*}{ RT $^{1}$} & \multirow{2}{*}{ Compound } & \multicolumn{3}{|c|}{$\mathrm{J}-1$} & \multicolumn{3}{|c|}{$\mathrm{J}-6$} & \multicolumn{3}{|c|}{$\mathrm{J}-8$} & \multicolumn{3}{|c|}{$\mathrm{J}-15$} \\
\hline & & & 1d & $2 d$ & $6 d$ & 1d & $2 d$ & $6 d$ & $1 d$ & $2 d$ & $6 d$ & 1d & $2 d$ & $6 d$ \\
\hline 1 & $10.45 \mathrm{~min}$ & Phenol & & & & & & + & & & & & & \\
\hline 2 & $11.58 \mathrm{~min}$ & Ethyl 3-hydroxybutyrate & & & & + & + & & & & & + & & + \\
\hline 3 & $13.27 \mathrm{~min}$ & Benzaldehyde, 3-methyl & + & + & + & + & + & + & + & + & + & + & + & + \\
\hline 4 & $13.91 \mathrm{~min}$ & Salicylic acid & & & + & & & & & & & & & \\
\hline 5 & $13.92 \mathrm{~min}$ & 3-Hydroxybenzoic acid & & & & & & & + & & & & & \\
\hline 6 & $14.27 \mathrm{~min}$ & 2,6-Dihydroxyacetophenone & + & & & & & & & & & & & \\
\hline 7 & $14.61 \mathrm{~min}$ & 2,6-Dihydroxybenzoic acid & + & & & & & & + & & & + & & \\
\hline 8 & $14.84 \mathrm{~min}$ & 2-Ethylhexanoic acid & & & + & & & + & & & + & & & + \\
\hline 9 & $16.81 \mathrm{~min}$ & $\begin{array}{l}\text { Benzeneacetic acid, } \\
\text { 3-pentadecyl ester }\end{array}$ & & & & & + & & & & & & & \\
\hline 10 & $17.19 \mathrm{~min}$ & 2-Methoxy-4-vinylphenol & & & & & & + & & & & & & \\
\hline 11 & $18.32 \mathrm{~min}$ & $\begin{array}{c}\text { 5,5'-Dimethoxy-3,3',7,7'- } \\
\text { tetramethyl-2,2,- } \\
\text { binaphthalene- } 1,1^{\prime}, 4,4^{\prime} \text {-tetrone }\end{array}$ & & & & & & & + & & & & & \\
\hline 12 & $19.81 \mathrm{~min}$ & Butylated Hydroxytoluene & & & + & + & + & + & + & + & + & + & + & + \\
\hline 13 & $20.42 \mathrm{~min}$ & Tyrosol, acetate & & & + & & & & & & & & & \\
\hline 14 & $22.12 \mathrm{~min}$ & $\begin{array}{c}\text { Cinnamic acid, } \\
\text { 4-hydroxy-3-methoxy-, } \\
\text { (5-hydroxy-2-hydroxymethyl- } \\
\text { 6-[2-(4-hydroxy-3- } \\
\text { methoxyphenyl)ethoxy }\end{array}$ & & & + & & & & & & & & & \\
\hline 15 & $22.79 \mathrm{~min}$ & $\begin{array}{l}\text { Benzenebutyric acid, } \\
\text { 2,3-dimethoxy- }\end{array}$ & & & & + & & & & & & & & \\
\hline 16 & $23.77 \mathrm{~min}$ & $\begin{array}{c}\text { 1,2-Benzenedicarboxylic acid, } \\
\text { butyl octyl ester }\end{array}$ & & & & & & & & & & & & + \\
\hline
\end{tabular}


Table 1. Cont.

\begin{tabular}{|c|c|c|c|c|c|c|c|c|c|c|c|c|c|c|}
\hline \multirow{2}{*}{ No. } & \multirow{2}{*}{ RT $^{1}$} & \multirow{2}{*}{ Compound } & \multicolumn{3}{|c|}{$\mathrm{J}-1$} & \multicolumn{3}{|c|}{$\mathrm{J}-6$} & \multicolumn{3}{|c|}{$\mathrm{J}-8$} & \multicolumn{3}{|c|}{$\mathrm{J}-15$} \\
\hline & & & $1 d$ & $2 d$ & $6 d$ & $1 d$ & $2 d$ & $6 d$ & $1 d$ & $2 d$ & $6 d$ & $1 d$ & $2 d$ & $6 d$ \\
\hline 17 & $23.77 \mathrm{~min}$ & $\begin{array}{l}\text { Phthalic acid, hept-3-yl } \\
\text { isobutyl ester }\end{array}$ & + & & & + & & & + & + & + & + & + & \\
\hline 18 & $24.64 \mathrm{~min}$ & n-Hexadecanoic acid & + & + & + & + & + & + & + & + & + & + & + & + \\
\hline 19 & $24.71 \mathrm{~min}$ & Dibutyl phthalate & + & + & + & + & + & + & + & + & + & + & + & + \\
\hline 20 & $26.51 \mathrm{~min}$ & Octadecanoic acid & + & + & + & + & + & + & + & + & + & + & + & + \\
\hline 21 & $30.14 \mathrm{~min}$ & Phenol, 2,4-bis(1-phenylethyl)- & & & + & & & & & & & & & + \\
\hline 22 & $31.79 \mathrm{~min}$ & $\begin{array}{c}\text { Chromone,2-[2-[3,4,5- } \\
\text { trimethoxyphenyl]ethenyl]- } \\
\text { 5,6,7,8-tetramethoxy-3-methyl- }\end{array}$ & + & & & & & & & & & & & \\
\hline 23 & $32.69 \mathrm{~min}$ & $\begin{array}{l}\text { 1-Hydroxy-2-(2,3,4,6-tetra-O- } \\
\text { acetyl-beta-D-glucopyranosyl)- } \\
\text { 9H-xanthene-3,6,7-triyl } \\
\text { triacetate }\end{array}$ & + & & + & & & & & & + & + & + & + \\
\hline
\end{tabular}

${ }^{1}$ RT: retention time.

\section{Discussion}

According to the guaiacol color test, the lignin degradation efficiency by rotation incubation should be higher than that by static incubation. This may indicate that the selected lignin-degrading microorganisms have a certain oxygen demand during the degradation process, which was similar to the conclusion of other researchers $[9,28]$. At the same time, simple mechanical movement may bring better mixing of matrix and microorganism and dissolving of medium. It was also observed that the $\mathrm{pH}$ of the basic culture medium increased during microbial consortium incubation, which was similar to findings reported in the literature [29].

It was reported that some microorganisms could break down lignin, but it was necessary to add glucose as an energy source [30]. In view of previous research, we also determined the degradation rates after adding glucose in the degradation experiments. Similar to these studies, in this research, microorganisms exhibited strong adaptability to glucose. The results showed that lignin with added glucose greatly improved the degradation efficiency when compared with lignin alone. These results echo the findings from other work that glucose addition may effectively improve lignin degradation by promoting the growth of microorganisms and secreting the ligninolytic enzymes [31].

In a lignin degradation system, the $\mathrm{pH}$ value has been reported to be an important factor [29]. $\mathrm{pH}$ is presumed to have certain impacts on lignin degradation, whether for degradation by a single microorganism or by microbial consortia. According to the literature, for most lignin-degrading systems, neutral conditions were better. For example, the optimal $\mathrm{pH}$ value of Aneuribacillus aneurilyticus was 7.6 [32] and that of Comasonas sp. B-9 was 7 [33]. DM-1, which is a lignin degradation microbial consortium reported in the literature, also preferred neutral conditions [29]. However, in this study, the lignin degradation performance was best when the initial $\mathrm{pH}$ of the culture medium was 4 . Better degradation under acidic conditions may also correspond to the microorganism consortium composition and enzyme activities of lignin-degrading enzymes. It was reported that under acidic conditions, the strain could produce more lignin-degrading enzymes, such as laccase, with high enzyme activity [34,35].

Many literature results have shown that rotation speed of incubation had a significant impact on the microbial degradation process of aromatic compounds and lignin. For example, ferulic acid degradation by Phomopsis liquidambari was carried out under shaking incubation conditions at an optimal speed of $180 \mathrm{rpm}$ [36]. Bacillus subtilis was used in the pretreatment process of corn stalks to remove lignin and improve the production capacity of subsequent products, during which the optimal rotation speed was $120 \mathrm{rpm}$ [15]. Pandoraea sp. B-6 degraded lignin and reached the highest degradation efficiency at $120 \mathrm{rpm}$ [37]. In 
this research, the results showed that the lignin degradation efficiencies of all microbial consortia reached $45 \%$ at $200 \mathrm{rpm}$ on the 6th day. The increase of rotation speed is beneficial to the growth of aerobic microorganisms [35]. Aerobic microorganisms played a greater role in the lignin degradation. Taking J-6 as an example, there were a large number of yeasts and aerobic bacteria in J-6. Oxygen supply can significantly enhance the growth of microorganisms and ultimately improve the degradation of lignin.

Lignin concentration is an important factor that affects degradation efficiency [7]. Due to the different compositions of the four groups, the effect of lignin concentration on degradation by J-1, J-6, J-8, and J-15 was quite different. The main fungi in J-1 and J-6 was yeast, and yeast growth was greatly affected by lignin concentration, according to our former study. Therefore, lignin concentration also has a significant effect on lignin degradation by J-1 and J-6. An advantage of microbial consortia is that they have the ability to adapt to different environments, including various lignin concentrations. However, domestication is important and required prior to lignin degradation experiments [38].

At the same time, degradation experiments at different temperatures showed that microbial communities had strong practical applications in a temperature range close to room temperature.

In summary, the main factors that affected lignin degradation efficiency were $\mathrm{pH}$, lignin concentration, and rotation speed. Under optimal conditions, the degradation efficiencies of the four microbial consortia in this study were above $45 \%$ after 6 days of incubation. The degradation efficiency of the J-6 microbial consortium reached $54 \%$ after $48 \mathrm{~h}$ with an initial lignin concentration of $0.5 \mathrm{~g} / \mathrm{L}$ at an initial $\mathrm{pH}$ value of 4 and rotation speed of $200 \mathrm{rpm}$. To the best of our knowledge, this study also demonstrated the superiority of the degradation ability of microbial consortia over other reported microorganisms (Table 2).

Table 2. Comparison of the degradation efficiency by J-6 and other microorganisms.

\begin{tabular}{cccc}
\hline Microbial Strains & Lignin Degradation\% & Degradation Time & Lignin Load \\
\hline Bacteria & & & \\
Bacillus flexus [7] & $20 \%$ & $9 \mathrm{~d}$ & $0.4 \mathrm{~g} / \mathrm{L}$ \\
Cupriavidus basilensis B-8 [37] & $38 \%$ & $7 \mathrm{~d}$ & $0.5 \mathrm{~g} / \mathrm{L}$ \\
Citrobacter freundii [9] & $49 \%$ & $6 \mathrm{~d}$ & $600 \mathrm{ppm}$ \\
Fungi & $35 \%$ & $10 \mathrm{~d}$ & $2.0 \mathrm{~g} / \mathrm{L}$ \\
Cladosporium sp. Bio-1 [39] & $83.50 \%$ & $30 \mathrm{~d}$ & $1.0 \mathrm{~g} / \mathrm{L}$ \\
Penicillium chrysogenum [40] & $36 \%$ & $10 \mathrm{~d}$ & $0.50 \%$ \\
Phellinus sp. [41] & $54 \%$ & $48 \mathrm{~h}$ & $0.5 \mathrm{~g} / \mathrm{L}$ \\
J-6 & &
\end{tabular}

Furthermore, to explain the higher lignin degradation efficiency of microbial consortia, the lignin degradation enzyme activity of the four microbial consortia was compared. Regarding the test results for the corresponding enzyme activities of the characteristics of lignin degradation of the four communities, the enzyme activities of J-1 and J-6 were closer, which may be related to the similar composition of J-1 and J-6. J-6 had similar laccase and $\mathrm{MnP}$ activities but higher LiP enzyme activity than the other microbial consortia, which explains why it had the highest lignin degradation efficiency. In this study, the highest laccase activity of the various microbial consortia reached $897.5 \pm 48.5 \mathrm{U} / \mathrm{L}(\mathrm{J}-15$ on the 2nd day), and the MnP activity reached 401.6 $\pm 41.1 \mathrm{U} / \mathrm{L}$ (J-1 on the 1st day). Meanwhile, compared with the performance of some bacteria, $\mathrm{LiP}$ was not produced in the degradation process [37]. The microbial consortia used in this study can produce three kinds of enzymes at the same time, with the highest activity of LiP reaching $691.9 \pm 71.1 \mathrm{U} / \mathrm{L}$ (J-6 on the 6th day). These results also proved that lignin degradation by microbial consortia was superior to that by a single microorganism.

The compositions of lignin-degrading microbial consortia correspond to their lignin degradation characteristics and performances [42]. Through the analysis of fungal composition, it was shown that Mortierella sp. was found in J-1, J-6, J-8, and J-15. This microorganism may degrade lignin or lignin-like structural substances. Gong and coworkers [43] also 
showed that Mortierella sp. has a higher degradation ability and faster degradation rate for low-ring PAHs (polycyclic aromatic hydrocarbons). The degradation ability of mixed microorganisms that were composed of Mortierella sp. and Pseudomonas sp. was better than that of a single microorganism. Meanwhile, the results show that a mixed consortium of fungi and bacteria was better than a single microorganism for degrading polymer compounds with benzene rings. The UPGMA algorithm was used to construct a tree structure to visually represent the degrees of similarity or difference in the consortium compositions of different samples. The difference in fungal consortium compositions of J-1 and J-6 was the smallest. The lignin degradation characteristics of J-1 and J-6 were also very similar.

Saccharomycetales in J-1 and J-6 accounted for $100 \%$ of the total amount of Saccharomycetales in the four groups. Fusarium sp. and Trichoderma sp. in J-15 accounted for the majority (more than 90\%). Fusarium sp. [44,45] and Trichoderma sp. [46] were reported in the literature with respect to lignin-degrading fungi but less was reported regarding Saccharomycetales. However, the lignin degradation efficiency of J-6 was relatively high, which indicated that the Saccharomycetales microorganism can survive in the lignin substrate media and may have promoted lignin degradation. In this study, glucose was added to the lignin degradation system, which promoted the reproduction of Saccharomycetales. At the same time, the culture conditions were acidic, which corresponded to the characteristics of yeast growth. To determine the effect of yeast on the activity of lignin-degrading enzymes, J-6 was treated with nystatin to inhibit yeast activity. The results indicated that yeast in the microbial consortium improved the enzyme activity of lignin-degrading enzymes and thus increased the lignin degradation efficiency. There are also similar reports in the literature; for example, SSlosarčíková et al. [47] reported that although yeast did not have the ability to degrade dye chemicals, it could survive in a biphenyl dye solution, and in a degradation system with yeast, the activity of lignin-degrading enzymes such as laccase was improved. In addition, it has been reported that yeast can produce lignin-degrading enzymes in the degradation system of benzene compounds [48]. Furthermore, the rapid growth of yeast and its consumption of glucose also promoted lignin utilization by other microorganisms in the consortium.

Through the analysis of bacterial composition, it was shown that Alcaligenaceae, Cupriavidus sp. and Serratia sp. were found in J-1, J-6, J-8, and J-15. These three microorganisms have also been reported in other literature. For example, a lignin-degrading consortium was obtained from a sugarcane plantation soil sample, and taxonomic analyses (based on $16 \mathrm{~S}$ rRNA) indicated the prevalence of Proteobacteria, Actinobacteria, and Firmicutes members, including the Alcaligenaceae and Micrococcaceae families, which were enriched in lignin-degrading consortia compared to sugarcane soil [49]. Kraft lignin was able to be used as the sole carbon source of Cupriavidus basilensis B-8, and $41.5 \%$ of the lignin, 37.7\% of the total carbon (TC), and $43.0 \%$ of the color were removed after 7 days of incubation [50]. Serratia sp. that was isolated from effluent-contaminated soil was able to degrade and detoxify pulp and paper mill effluent with significant lignin reductions [51]. Further studies to identify the common microorganisms in different lignin-degrading consortia can provide insights into obtaining lignin-degrading bacteria. J-6 had the highest abundance, while J-8 had the lowest bacterial abundance. J-6 mainly included Shinella sp., Cupriavidus sp., Bosea sp., Bacillus sp., Rhodococcus sp., and Pseudomonas sp. These types of microorganisms have some applications in the field of lignin degradation. For example, laccase genes in the genera Shinella sp. were detected, which indicated that its metabolic activity was related to lignin degradation [52]. Bosea sp. and Bacillus sp. can also produce laccase enzyme for lignin degradation [53]. Some bacteria belonging to Rhodococcus sp. have been determined to have the capability to degrade lignin, and among various Rhodococcus species, $R$. jostii RHA1 is the one that has been studied most often [13]. A bacterial peroxidase was purified from Pseudomonas sp. SUK1, and this 86-kDa heme-containing peroxidase showed optimal activity on a range of lignin-related phenols [53]. In summary, according to our lignin degradation performance results and consortium taxonomic analyses, the reason for the high degradation efficiency of J-6 was the presence of abundant bacterial communities. 
All four microbial consortia had certain lignin degradation abilities. Lignin degradation may be carried out by fungi or bacteria, and through the synergies between fungi and bacteria, the degradation ability of lignin was improved. Combined with results of our degradation experiments, the impact of rotation speed and lignin concentration on bacteria was more obvious, while that on fungal lignin degradation was smaller.

According to other literature $[5,54,55]$, the types of lignin degradation products included benzene acetic acid compounds, benzaldehyde compounds, cinnamic acid compounds, phenol-based compounds, benzoic acid compounds, benzyl benzoate compounds, phthalate compounds, benzyl alcohol compounds, veratryl alcohol compounds, guaiacol compounds, vanillin compounds, acetophenone compounds, and phenyl acetate compounds. In this study, the classes of products that resulted from digestion by the four microbial consortia included benzaldehyde compounds, benzoic acid compounds, phenol, benzene acetic acid compounds, acetophenone, and phthalate ester compounds, and the types of intermediate products that were produced in the degradation process were also detected and reported, which provided a basis for future research on lignin degradation products. Hexadecanoic acid and octadecanoic acid, which were products obtained in this study, were also detected in the GC analysis of lignin degradation by other microorganisms [4]. Lignin degradation by J-6 was relatively complete, which also indicated that lignin degradation by bacterial communities was more complete than that by fungal communities [21].

\section{Materials and Methods}

\subsection{Materials}

The samples for lignin degradation microbial consortium screening were collected from the Jingzhou Museum of Hubei Province $\left(30^{\circ} 21^{\prime} 20^{\prime \prime} \mathrm{N}, 112^{\circ} 10^{\prime} 30^{\prime \prime} \mathrm{E}\right)$. The wooden antiques consisted mainly of wooden components, chime frames, wooden wares, and coffins that were unearthed from the No. M190 noble tomb of Zeng State (the middle of the Spring and Autumn period from approximately 2600 years ago) in Zaoshulin, Suizhou, Hubei Province. Wood chips that were scattered on the surface of the antiques and their soaking water samples were collected in sterile sampling bags/tubes, sealed and frozen for transportation. Then, these samples were stored at $4{ }^{\circ} \mathrm{C}$ in a refrigerator. The alkali lignin used in the experiment was purchased from Sigma with a molecular weight of 10,000 (CAS:8068-05-1). Other reagents (analytical grade) were purchased from the Beijing Chemical Factory.

\subsection{Culture Conditions}

The primary screening medium contained peptone $2.5 \mathrm{~g} / \mathrm{L}, \mathrm{KH}_{2} \mathrm{PO}_{4} 1 \mathrm{~g} / \mathrm{L}, \mathrm{NaCl}$ $2.5 \mathrm{~g} / \mathrm{L}, \mathrm{MgSO}_{4} \cdot 7 \mathrm{H}_{2} \mathrm{O} 0.2 \mathrm{~g} / \mathrm{L}, \mathrm{CaCl}_{2} 0.1 \mathrm{~g} / \mathrm{L}$, guaiacol $1 \mathrm{~mL} / \mathrm{L}$ and trace elements $1 \mathrm{~mL} / \mathrm{L}$. The basic culture medium for screening contained peptone $2.5 \mathrm{~g} / \mathrm{L}, \mathrm{KH}_{2} \mathrm{PO}_{4} 1 \mathrm{~g} / \mathrm{L}, \mathrm{NaCl}$ $2.5 \mathrm{~g} / \mathrm{L}, \mathrm{MgSO}_{4} \cdot 7 \mathrm{H}_{2} \mathrm{O} 0.2 \mathrm{~g} / \mathrm{L}, \mathrm{CaCl}_{2} 0.1 \mathrm{~g} / \mathrm{L}$, different carbon sources and trace elements $1 \mathrm{~mL} / \mathrm{L}$. The trace element solution included $\mathrm{ZnSO}_{4} \cdot 7 \mathrm{H}_{2} \mathrm{O} 0.1 \mathrm{~g} / \mathrm{L}, \mathrm{CoCl}_{2} \cdot 6 \mathrm{H}_{2} \mathrm{O} 0.16 \mathrm{~g} / \mathrm{L}$, $\mathrm{CuSO}_{4} \cdot 5 \mathrm{H}_{2} \mathrm{O} 0.15 \mathrm{~g} / \mathrm{L}, \mathrm{MnSO}_{4} \cdot \mathrm{H}_{2} \mathrm{O} 0.1 \mathrm{~g} / \mathrm{L}, \mathrm{H}_{3} \mathrm{BO}_{3} 0.02 \mathrm{~g} / \mathrm{L}, \mathrm{Na}_{2} \mathrm{MoO}_{4} \cdot 2 \mathrm{H}_{2} \mathrm{O} 0.8 \mathrm{~g} / \mathrm{L}$, and $\mathrm{NiCl}_{2} \cdot 6 \mathrm{H}_{2} \mathrm{O} 0.05 \mathrm{~g} / \mathrm{L}$, and the $\mathrm{pH}$ was the original value, which was 6.08 [29]. The medium for the lignin degradation test contained ammonium sulfate $2.5 \mathrm{~g} / \mathrm{L}, \mathrm{KH}_{2} \mathrm{PO}_{4}$ $1 \mathrm{~g} / \mathrm{L}, \mathrm{NaCl} 2.5 \mathrm{~g} / \mathrm{L}, \mathrm{MgSO}_{4} \cdot 7 \mathrm{H}_{2} \mathrm{O} 0.2 \mathrm{~g} / \mathrm{L}, \mathrm{CaCl}_{2} 0.1 \mathrm{~g} / \mathrm{L}$, glucose $0.5 \mathrm{~g} / \mathrm{L}$, trace element $1 \mathrm{~mL} / \mathrm{L}$ and alkali lignin of different concentrations.

\subsection{Screening of Microbial Consortia}

Samples $(1 \mathrm{~g})$ were added to sterilized normal saline $(9 \mathrm{~mL})$, stirred for $30 \mathrm{~min}$, and were then allowed to stand for $10 \mathrm{~min}$. Then, $2 \mathrm{~mL}$ of supernatant was selected and added to $18 \mathrm{~mL}$ of primary screening medium and incubated at $30^{\circ} \mathrm{C}$ for $7 \mathrm{~d}$ without shaking. Another $2 \mathrm{~mL}$ of supernatant was transferred to the basic medium $(18 \mathrm{~mL})$, which also contained guaiacol at a concentration of $1 \mathrm{~mL} / \mathrm{L}$, and cultured at $120 \mathrm{rpm}$ and $30{ }^{\circ} \mathrm{C}$ for $7 \mathrm{~d}$. The purpose of static culture and shock culture was to test the effect of oxygen on 
microbial consortium growth. After 7 days, the medium color was observed. The red and pink media after static incubation and rotation incubation were selected. Five milliliters of microbial suspension were added to $45 \mathrm{~mL}$ of basic culture medium containing alkali lignin at a concentration of $1 \mathrm{~g} / \mathrm{L}$ for the second screening, which was followed by static or rotation $(160 \mathrm{rpm})$ incubation at $30^{\circ} \mathrm{C}$ for 7 days. The microbial suspension obtained from the second screening was transferred to a lignin degradation medium with a lignin concentration of $0.5 \mathrm{~g} / \mathrm{L}$ and $10 \%$ inoculum volume. The microbial were cultured at $\mathrm{pH} 7$, $30^{\circ} \mathrm{C}$, and $160 \mathrm{rpm}$ for $7 \mathrm{~d}$. The microbial consortia with relatively high lignin degradation efficiencies were selected for the lignin degradation experiments.

\subsection{Lignin Degradation Experiments}

Three cycles of incubation in the lignin degradation medium were carried out prior to the lignin degradation experiments. Consortium composition analyses of the lignin degradation microbial consortia after stable culture were carried out. The lignin degradation experiment was carried out by changing the culture conditions. The control was set as the same operation mode without adding microorganisms. Culture conditions, including the carbon source ("lignin alone" and "lignin plus glucose"), $\mathrm{pH}(4-8)$, rotation speed (120 rpm, $160 \mathrm{rpm}$ and $200 \mathrm{rpm}$; on a shaking incubator with a rotational radius of $10 \mathrm{~cm}$ ), and lignin concentration $(0.2-2 \mathrm{~g} / \mathrm{L})$, were changed to obtain the optimal degradation efficiency.

\subsection{Analytical Methods}

Microbial consortium genomic DNA was extracted from the samples using the E.Z.N.A. ${ }^{\circledR}$ soil DNA Kit (Omega Bio-Tek, Norcross, GA, USA). The bacterial 16S rRNA gene was amplified with the primer pair 515F (5'-GTGCCAGCMGCCGCGG-3') and 806R (5'-GGACTACHVGGGTWTCTAAT-3'). The fungal ITS gene was amplified with the primer pair ITS1F ( $5^{\prime}$-CTTGGTCATTTAGAGGAAGTAA-3') and ITS2R (5'-GCTGCGTTCTTCATCG ATGC-3') by an ABI GeneAmp ${ }^{\circledR} 9700$ PCR thermocycler (ABI, CA, California, USA). The purified amplicons were sequenced on an Illumina MiSeq PE300 platform/NovaSeq PE250 platform (Illumina, San Diego, CA, USA). The raw reads were deposited into the NCBI Sequence Read Archive (SRA) database (Accession Number: PRJNA666498). The sequence data processing method was carried out according to the literature [56-58]. Enzyme activities for lignin degradation (laccase, $\mathrm{LiP}$, and $\mathrm{MnP}$ ) were determined according to the literature [37]. Laccase activity was measured by monitoring the oxidation of ABTS. Lip activity was measured by monitoring the oxidation of veratryl alcohol. MnP activity was measured by monitoring the oxidation of 2, 6-DMP. When measuring the enzyme activity of the J-6 bacterial consortium, $0.1 \mathrm{~g} / \mathrm{L}$ nystatin was directly added to the J- 6 consortium. After a shaking treatment for $1 \mathrm{~h}$, the cells were transferred to a culture medium that contained $0.1 \mathrm{~g} / \mathrm{L}$ nystatin and were cultured for $12 \mathrm{~h}$. The cells were then transferred to a nystatin medium and were cultured for $12 \mathrm{~h}$ again to obtain a J-6 bacterial consortium.

The lignin concentration was measured by measuring the absorbance at $280 \mathrm{~nm}$ according to a previously reported method [59]. The lignin degradation efficiency was calculated as follows:

Degradation efficiency $(\%)=($ initial lignin concentration - lignin concentration after treatment)/initial lignin concentration.

GC-MS analysis of the lignin degradation products was conducted according to the reference [37]. Fungal and bacterial biomasses were measured by a classic method called the respiratory inhibition method [60]. Agar slices were used for microscopic examination of microbial consortia, and samples were placed in a microscope (cx23, Olympus, Japan) for microscopic examination.

\subsection{Statistical Methods}

All of the above experiments were repeated in triplicate, and the average data were reported. One-way ANOVA with Tukey's test was used to detect any significant differences among treatments $(p<0.05)$. 


\section{Conclusions}

Interest in biological lignin degradation has been widely presented in the field of biomass utilization and wastewater treatment containing lignin compounds. In this study, we used antique wood samples as a novel, to the best of our knowledge, source for screening lignin degradation microbial consortia. Four microbial consortia, namely, J-1, J-6, J-8, and J-15, with lignin degradation capabilities were obtained, among which the J-6 microbial consortium was the most efficient, as was supported by the appearance of three lignin degradation enzymes with higher activities. The degradation efficiency of the J-6 microbial consortium reached $54 \%$ after $48 \mathrm{~h}$ with an initial lignin concentration of $0.5 \mathrm{~g} / \mathrm{L}$ at an initial $\mathrm{pH}$ value of 4 and rotation speed of $200 \mathrm{rpm}$. Lignin degradation by J-6 was relatively complete, and there were no degradation products containing multiple benzene rings. The fungal consortium of J-6 was mainly composed of Saccharomycetales $98.92 \%$ and Ascomycota $0.56 \%$, which accounted for $31 \%$ of the total biomass. Saccharomycetales adapted to the lignin substrate and promoted lignin degradation. Yeast in the microbial consortium improved the enzyme activity of lignin-degrading enzymes and thus increased the lignin degradation efficiency. The main bacteria in J-6 were Shinella sp. $47.38 \%$, Cuprividus sp. $29.84 \%$, and Bosea sp. $7.96 \%$. The abundance of the bacterial consortium in J-6 may also be beneficial for lignin degradation. The J-6 microbial consortium demonstrated promising potential for applications with lignin degradation/removal purposes.

Author Contributions: Data curation, W.Z. and X.R.; Formal analysis, W.Z. and X.R.; Methodology, W.Z. and X.R.; Project administration, L.W.; Resources, Q.L.; Supervision, Q.L.; Writing—original draft, W.Z.; Writing—review \& editing, L.W. All authors have read and agreed to the published version of the manuscript.

Funding: This research was supported by the Natural Science Foundation of Zhejiang Province under Grant No. LQ20B060004, National Natural Science Foundation of China (No. 21476190; 21606005), Zhejiang Shuren University Basic Scientific Research Special Funds (2021XZ016) (W.Z.), and institutional fund from the Westlake University/Westlake Institute for Advanced Study (X.R. and L.W.).

Institutional Review Board Statement: Not applicable.

Informed Consent Statement: Not applicable.

Data Availability Statement: Most of the recorded data are available in all tables and figures in the manuscript and supplementary material.

Acknowledgments: We thank the instructional support of GC-MS analysis from Zhibin Wang of Yanshan University.

Conflicts of Interest: The authors declare no conflict of interest.

Sample Availability: Samples of the compounds are not available from the authors.

\section{References}

1. Pu, W.F.; Shen, C.; Wei, B.; Yang, Y.; Li, Y.B. A comprehensive review of polysaccharide biopolymers for enhanced oil recovery (EOR) from flask to field. J. Ind. Eng. Chem. 2018, 61, 1-11. [CrossRef]

2. Lubbers, R.J.; Dilokpimol, A.; Visser, J.; Mäkelä, M.R.; Hildén, K.S.; de Vries, R.P. A comparison between the homocyclic aromatic metabolic pathways from plant-derived compounds by bacteria and fungi. Biotechnol. Adv. 2019, 37, 107396. [CrossRef] [PubMed]

3. Houtman, C.J.; Maligaspe, E.; Hunt, C.G.; Fernández-Fueyo, E.; Martínez, A.T.; Hammel, K.E. Fungal lignin peroxidase does not produce the veratryl alcohol cation radical as a diffusible ligninolytic oxidant. J. Biol. Chem. 2018, 293, 4702-4712. [CrossRef]

4. Kumar, M.; Oyedun, A.O.; Kumar, A. A review on the current status of various hydrothermal technologies on biomass feedstock. Renew. Sustain. Energy Rev. 2018, 81, 1742-1770. [CrossRef]

5. Asina, F.; Brzonova, I.; Kozliak, E.; Kubátová, A.; Ji, Y. Microbial treatment of industrial lignin: Successes, problems and challenges. Renew. Sustain. Energy Rev. 2017, 77, 1179-1205. [CrossRef]

6. Kamimura, N.; Sakamoto, S.; Mitsuda, N.; Masai, E.; Kajita, S. Advances in microbial lignin degradation and its applications. Curr. Opin. Biotechnol. 2019, 56, 179-186. [CrossRef] [PubMed] 
7. Kumar, A.; Priyadarshinee, R.; Singha, S.; Sengupta, B.; Roy, A.; Dasgupta, D.; Mandal, T. Biodegradation of alkali lignin by Bacillus flexus RMWW II: Analyzing performance for abatement of rice mill wastewater. Water Sci. Technol. 2019, 80, 1623-1632. [CrossRef]

8. Zhang, Y.; Zang, G.-Q.; Tang, Z.-H.; Chen, X.-H.; Yu, Y.-S. Burning straw, air pollution, and respiratory infections in China. Am. J. Infect. Control 2014, 42, 815. [CrossRef]

9. Arun, A.; Eyini, M. Comparative studies on lignin and polycyclic aromatic hydrocarbons degradation by basidiomycetes fungi. Bioresour. Technol. 2011, 102, 8063-8070. [CrossRef]

10. Bugg, T.D.; Williamson, J.J.; Rashid, G.M. Bacterial enzymes for lignin depolymerisation: New biocatalysts for generation of renewable chemicals from biomass. Curr. Opin. Chem. Biol. 2020, 55, 26-33. [CrossRef]

11. Ho, J.C.H.; Pawar, S.V.; Hallam, S.J.; Yadav, V.G. An Improved Whole-Cell Biosensor for the Discovery of Lignin-Transforming Enzymes in Functional Metagenomic Screens. ACS Synth. Biol. 2018, 7, 392-398. [CrossRef]

12. Li, C.; Chen, C.; Wu, X.; Tsang, C.-W.; Mou, J.; Yan, J.; Liu, Y.; Lin, C.S.K. Recent advancement in lignin biorefinery: With special focus on enzymatic degradation and valorization. Bioresour. Technol. 2019, 291, 121898. [CrossRef]

13. Chen, Z.; Wan, C. Biological valorization strategies for converting lignin into fuels and chemicals. Renew. Sustain. Energy Rev. 2017, 73, 610-621. [CrossRef]

14. Becker, J.; Kuhl, M.; Kohlstedt, M.; Starck, S.; Wittmann, C. Metabolic engineering of Corynebacterium glutamicum for the production of cis, cis-muconic acid from lignin. Microb. Cell Fact. 2018, 17, 115. [CrossRef]

15. Xu, W.; Fu, S.; Yang, Z.; Lu, J.; Guo, R. Improved methane production from corn straw by microaerobic pretreatment with a pure bacteria system. Bioresour. Technol. 2018, 259, 18-23. [CrossRef]

16. Lv, Y.; Chen, Y.; Sun, S.; Hu, Y. Interaction among multiple microorganisms and effects of nitrogen and carbon supplementations on lignin degradation. Bioresour. Technol. 2014, 155, 144-151. [CrossRef]

17. Wei, Y.Q.; Wu, D.; Wei, D.; Zhao, Y.; Wu, J.Q.; Xie, X.Y.; Zhang, R.J.; Wei, Z.M. Improved lignocellulose-degrading performance during straw composting from diverse sources with actinomycetes inoculation by regulating the key enzyme activities. Bioresour. Technol. 2019, 27, 66-74. [CrossRef] [PubMed]

18. Rahmanpour, R.; Rea, D.; Jamshidi, S.; Fülop, V.; Bugg, T.D.H. Structure of Thermobifida fusca DyP-type peroxidase and activity towards Kraft lignin and lignin model compounds. Arch. Biochem. Biophys. 2016, 594, 54-60. [CrossRef] [PubMed]

19. Zhang, S.; Xiao, J.; Wang, G.; Chen, G. Enzymatic hydrolysis of lignin by ligninolytic enzymes and analysis of the hydrolyzed lignin products. Bioresour. Technol. 2020, 304, 122975. [CrossRef]

20. Chauhan, P.S. Role of various bacterial enzymes in complete depolymerization of lignin: A review. Biocatal. Agric. Biotechnol. 2020, 23, 101498. [CrossRef]

21. Wilhelm, R.C.; Singh, R.; Eltis, L.D.; Mohn, W.W. Bacterial contributions to delignification and lignocellulose degradation in forest soils with metagenomic and quantitative stable isotope probing. ISME J. 2019, 13, 413-429. [CrossRef] [PubMed]

22. Ali, S.S.; Abomohra, A.E.; Sun, J.Z. Effective bio-pretreatment of sawdust waste with a novel microbial consortium for enhanced biomethanation. Bioresour Technol. 2017, 238, 425-432. [CrossRef]

23. Wang, Y.X.; Liu, Q.; Yan, L.; Gao, Y.M.; Wang, Y.J.; Wang, W.D. A novel lignin degradation bacterial consortium for efficient pulping. Bioresour. Technol. 2013, 139, 113-119. [CrossRef] [PubMed]

24. Ma, X.C.; Li, X.K.; Wang, X.W.; Liu, G.G.; Zuo, J.L.; Wang, S.T.; Wang, K. Impact of salinity on anaerobic microbial consortium structure in high organic loading purified terephthalic acid wastewater treatment system. J. Hazard. Mater. 2020, $383,121132$. [CrossRef] [PubMed]

25. Kim, Y.S.; Singh, A.P.; Nilsson, T. Bacteria as Important Degraders in Waterlogged Archaeological Woods. Holzforschung 1996, 50, 389-392. [CrossRef]

26. Guo, J.; Zhou, H.; Stevanic, J.S.; Dong, M.; Min, Y.; Lennart, S.; Yin, Y.F. Effects of ageing on the cell wall and its hygroscopicity of wood in ancient timber construction. Wood Sci. Technol. 2017, 52, 131-147. [CrossRef]

27. Hu, D. The antisepsis of the bamboo slips and lacquer wares in water. Sci. Conserv. Archaeol. 2003, 15, 14-19.

28. Wang, W.D.; Yan, L.; Cui, Z.J.; Gao, Y.M.; Wang, Y.J.; Jing, R.Y. Characterization of a microbial consortium capable of degrading lignocellulose. Bioresour. Technol. 2011, 102, 9321-9324. [CrossRef]

29. Fang, X.; Li, Q.; Lin, Y.; Lin, X.; Dai, Y.; Guo, Z.; Pan, D. Screening of a microbial consortium for selective degradation of lignin from tree trimmings. Bioresour. Technol. 2018, 254, 247-255. [CrossRef]

30. Zhu, D.; Zhang, P.; Xie, C.; Zhang, W.; Sun, J.; Qian, W.-J.; Yang, B. Biodegradation of alkaline lignin by Bacillus ligniniphilus L1. Biotechnol. Biofuels 2017, 10, 44. [CrossRef]

31. Wu, J.; Xiao, Y.-Z.; Yu, H.-Q. Degradation of lignin in pulp mill wastewaters by white-rot fungi on biofilm. Bioresour. Technol. 2005, 96, 1357-1363. [CrossRef] [PubMed]

32. Raj, A.; Chandra, R.; Reddy, M.; Purohit, H.J.; Kapley, A. Biodegradation of kraft lignin by a newly isolated bacterial strain, Aneurinibacillus aneurinilyticus from the sludge of a pulp paper mill. World J. Microbiol. Biotechnol. 2006, 23, 793-799. [CrossRef]

33. Chen, Y.H.; Chai, L.Y.; Zhu, Y.H.; Yang, Z.H.; Zheng, Y.; Zhang, H. Biodegradation of kraft lignin by a bacterial strain Comamonas sp. B-9 isolated from eroded bamboo slips. J. Appl. Microbiol. 2012, 112, 900-906. [CrossRef]

34. Christopher, L.P.; Yao, B.; Ji, Y. Lignin biodegradation with laccase-mediator systems. Front. Energy Res. 2014, 2, 12. [CrossRef]

35. Mate, D.M.; Alcalde, M. Laccase: A multi-purpose biocatalyst at the forefront of biotechnology. Microb. Biotechnol. 2017, 10, 1457-1467. [CrossRef] 
36. Xie, X.-G.; Dai, C.-C. Degradation of a model pollutant ferulic acid by the endophytic fungus Phomopsis liquidambari. Bioresour. Technol. 2015, 179, 35-42. [CrossRef]

37. Shi, Y.; Chai, L.Y.; Tang, C.J.; Yang, Z.H.; Zheng, Y.; Chen, Y.H.; Jing, Q.X. Biochemical investigation of kraft lignin degradation by Pandoraea sp. B-6 isolated from bamboo slips. Bioproc. Biosyst. Eng. 2013, 36, 1957-1965. [CrossRef]

38. Zhang, W.; Ren, X.H.; He, J.; Zhang, Q.R.; Qiu, C.; Fan, B.M. Application of natural mixed bacteria immobilized carriers to different kinds of organic wastewater treatment and microbial consortium comparison. J. Hazard. Mater. 2019, 377, 113-123. [CrossRef] [PubMed]

39. Chandra, R.; Bharagava, R.N. Bacterial degradation of synthetic and kraft lignin by axenic and mixed culture and their metabolic products. J. Environ. Biol. 2013, 34, 991-999.

40. Jin, R. Identification and characterization of a fungal strain with lignin and cellulose hydrolysis activities. Afr. J. Microbiol. Res. 2012, 6, 6545-6550. [CrossRef]

41. Rodríguez, A.; Carnicero, A.; Perestelo, F.; Fuente, D.G.; Milstein, O.; Falcón, M.A. Effect of Penicillium chrysogenum on lignin transformation. Appl. Environ. Microbiol. 1994, 60, 2971-2976. [CrossRef] [PubMed]

42. Song, N.; Xu, H.C.; Yan, Z.S.; Yang, T.; Wang, C.H.; Jiang, H.L. Improved lignin degradation through distinct microbial consortium in subsurface sediments of one eutrophic lake. Renew. Energy 2019, 138, 861-869. [CrossRef]

43. Gong, C.J.; Su, D.; Wang, X.; Pu, Y.; Wang, T.J. Impacts of cold-resistant mixed strains immobilized by different carrier materials on remediation of PAHs polluted soils. Chin. J. Ecol. 2018, 37, 3713-3720.

44. Madadi, M.; Hano, A. Lignin Degradation by Fungal Pretreatment: A Review. J. Plant Pathol. Microbiol. 2017, 8, 1-6.

45. Bugg, T.D.H.; Ahmad, M.; Hardiman, E.; Rahman, P.R. ChemInform Abstract: Pathways for Degradation of Lignin in Bacteria and Fungi. Nat. Prod. Rep. 2011, 28, 1883-1896. [CrossRef]

46. Young, D.; Dollhofer, V.; Callaghan, T.M.; Reitberger, S.; Lebuhn, M.; Benz, J.P. Isolation, identification and characterization of lignocellulolytic aerobic and anaerobic fungi in one- and two-phase biogas plants. Bioresour. Technol. 2018, 268, 470-479. [CrossRef] [PubMed]

47. Šlosarčíková, P.; Novotný, Č.; Malachová, K.; Válková, H.; Fojtík, J. Effect of yeasts on biodegradation potential of immobilized cultures of white rot fungi. Sci. Total Environ. 2017, 589, 146-152. [CrossRef] [PubMed]

48. Yang, Q.; Yediler, A.; Yang, M.; Kettrup, A. Decolorization of an azo dye, Reactive Black 5 and MnP production by yeast isolate: Debaryomyces polymorphus. Biochem. Eng. J. 2005, 24, 249-253. [CrossRef]

49. Moraes, E.C.; Alvarez, T.M.; Persinoti, G.F.; Tomazetto, G.; Brenelli, L.B.; Paixão, D.A.A.; Ematsu, G.C.; Aricetti, J.A. Lignolyticconsortium omics analyses reveal novel genomes and pathways involved in lignin modification and valorization. Biotechnol. Biofuels 2018, 11, 75. [CrossRef]

50. Shi, Y.; Yan, X.; Li, Q.; Wang, X.; Liu, M.; Xie, S.S.; Chai, L.Y.; Yuan, J.S. Directed bioconversion of Kraft lignin to polyhydroxyalkanoate by Cupriavidus basilensis B-8 without any pretreatment. Process Biochem. 2017, 52, 238-242. [CrossRef]

51. Singh, A.K.; Yadav, P.; Bharagava, R.N.; Saratale, G.D.; Raj, A. Biotransformation and Cytotoxicity Evaluation of Kraft Lignin Degraded by Ligninolytic Serratia liquefaciens. Front. Microbiol. 2019, 10, 2364. [CrossRef] [PubMed]

52. Wang, L.; Nie, Y.; Tang, Y.-Q.; Song, X.-M.; Cao, K.; Sun, L.-Z.; Wang, Z.-J.; Wu, X.-L. Diverse Bacteria with Lignin Degrading Potentials Isolated from Two Ranks of Coal. Front. Microbiol. 2016, 7, 1428. [CrossRef] [PubMed]

53. Tian, J.-H.; Pourcher, A.-M.; Bouchez, T.; Gelhaye, E.; Peu, P. Occurrence of lignin degradation genotypes and phenotypes among prokaryotes. Appl. Microbiol. Biotechnol. 2014, 98, 9527-9544. [CrossRef]

54. Brown, M.E.; Chang, M.C. Exploring bacterial lignin degradation. Curr. Opin. Chem. Biol. 2014, 19, 1-7. [CrossRef] [PubMed]

55. Azadi, P.; Inderwildi, O.R.; Farnood, R.; King, D.A. Liquid fuels, hydrogen and chemicals from lignin: A critical review. Renew. Sustain. Energy Rev. 2013, 21, 506-523. [CrossRef]

56. Chen, S.; Zhou, Y.; Chen, Y.; Gu, J. fastp: An ultra-fast all-in-one FASTQ preprocessor. Bioinformatics 2018, 34, i884-i890. [CrossRef]

57. Magoč, T.; Magoč, M.; Salzberg, S.L. FLASH: Fast Length Adjustment of Short Reads to Improve Genome Assemblies. Bioinformatics 2011, 27, 2957-2963. [CrossRef]

58. Edgar, R.C. UPARSE: Highly accurate OTU sequences from microbial amplicon reads. Nat. Methods 2013, 10, 996-998. [CrossRef]

59. Chang, Y.-C.; Choi, D.; Takamizawa, K.; Kikuchi, S. Isolation of Bacillus sp. strains capable of decomposing alkali lignin and their application in combination with lactic acid bacteria for enhancing cellulase performance. Bioresour. Technol. 2014, 152, 429-436. [CrossRef]

60. Anderson, J.P.E.; Domsch, K.H. Measurement of bacterial and fungal contributions to respiration of selected agricultural and forest soils. Can. J. Microbiol. 1975, 21, 314-322. [CrossRef] 